\title{
Supply Chain Flexibility in Dynamic Environments:
}

The Enabling Role of Operational Absorptive Capacity and Organisational

\section{Learning}

Araceli Rojo*, Mark Stevenson**, Javier Llorens-Montes*, and Maria Nieves Perez-

Arostegui*

* University of Granada, Spain; ** Lancaster University, U.K.

\section{Abstract}

Purpose: To analyse the relationship between environmental dynamism and Supply Chain Flexibility (SCF); and to evaluate if two dynamic capabilities, i.e. Operational Absorptive Capacity (OAC) and Organisational Learning (OL), are necessary competences for firms to develop such a responsive supply chain strategy as flexibility.

Design/methodology/approach: Hypothesised relationships are tested with survey data from 302 Spanish manufacturing firms using structural equations modeling.

Findings: Environmental dynamism is positively associated with both OAC and OL; and both dynamic capabilities enable SCF. We also find that the relationship between environmental dynamism and SCF is partially mediated by both dynamic capabilities.

Research implications: The study contributes to the literature, for example, by determining when it is advantageous to develop SCF; by specifying what capabilities a firm needs to develop to align SCF with the environment; and, by opening the black box that is the relationship between the environment and SCF.

Practical implications: Managers should develop SCF via OAC and OL when they detect a high degree of environmental dynamism. Knowing when this is necessary relies on a good understanding of the environment. OAC is found to be a stronger enabler of SCF than OL. The findings provide managers with an insight into why some firms are able to develop more effective responses to dynamic environments than others.

Originality/value: One of only a limited number of studies to adopt a dynamic capabilities approach to supply chain management. Prior literature has shown dynamic capabilities can aid in developing strategic, structural, and operational flexibility. We extend this literature by showing that OAC and OL have an effect on SCF.

Keywords: Supply chain flexibility; environmental dynamism; absorptive capacity; organisational learning; survey. 


\section{Author Biographies and Acknowledgments}

Araceli Rojo ( $\mathrm{PhD}$, University of Granada) is a Lecturer in business administration at the University of Granada, Spain. Her research interests are in supply chain management, flexibility management, and organisational learning. Her work has been published in Supply Chain Management: An International Journal.

Mark Stevenson is a Professor of Operations Management at Lancaster University in the UK. He has published various articles broadly on the theme of coping with change in supply chains, including on supply chain flexibility, supply chain uncertainty, supply chain resilience, and sustainability risks in supply chains. His work has appeared in several operations and supply chain journals, including the International Journal of Operations \& Production Management (IJOPM), Production \& Operations Management (POM), the International Journal of Production Economics (IJPE), and the International Journal of Production Research (IJPR). He regularly attends and presents his work at international conferences, including the European Operations Management Association (EurOMA) conference and the Production \& Operations Management Society (POMS) conference.

Javier Llorens-Montes is a Full Professor of quality management and business administration at the University of Granada, Spain. His current research focus is on quality management and flexibility management. The results of his research have been published in journals such as the Journal of Operations Management (JOM), International Journal of Production Research (IJPR), Omega, International Journal of Production Economics (IJPE), and International Journal of Operations \& Production Management (IJOPM).

Maria Nieves Perez-Arostegui (PhD, University of Granada) is an Associate Professor of business administration at the University of Granada, Spain. Her research is focused on quality management, operations management, and information technology. She has had papers published in the Journal of Computer Information Systems, Industrial Management and Data Systems, Total Quality Management and Business Excellence, BRQ Business Research Quarterly, International Journal of Operations and Production Management, and Supply Chain Management: An International Journal. 
Acknowledgments: This study received support and financing from the Spanish Ministry of Economy and Competitiveness (ECO2010-15885 and ECO2013-47027-P), from the Andalusian Regional Government (P11-SEJ-7294), and the European Union (FEDER). 


\section{Supply Chain Flexibility in Dynamic Environments: \\ The Enabling Role of Operational Absorptive Capacity and Organisational \\ Learning}

\section{Abstract}

Purpose: To analyse the relationship between environmental dynamism and Supply Chain Flexibility (SCF); and to evaluate if two dynamic capabilities, i.e. Operational Absorptive Capacity (OAC) and Organisational Learning (OL), are necessary competences for firms to develop such a responsive supply chain strategy as flexibility.

Design/methodology/approach: Hypothesised relationships are tested with survey data from 302 Spanish manufacturing firms using structural equations modeling.

Findings: Environmental dynamism is positively associated with both OAC and OL; and both dynamic capabilities enable SCF. We also find that the relationship between environmental dynamism and SCF is partially mediated by both dynamic capabilities.

Research implications: The study contributes to the literature, for example, by determining when it is advantageous to develop SCF; by specifying what capabilities a firm needs to develop to align SCF with the environment; and, by opening the black box that is the relationship between the environment and SCF.

Practical implications: Managers should develop SCF via OAC and OL when they detect a high degree of environmental dynamism. Knowing when this is necessary relies on a good understanding of the environment. OAC is found to be a stronger enabler of SCF than OL. The findings provide managers with an insight into why some firms are able to develop more effective responses to dynamic environments than others.

Originality/value: One of only a limited number of studies to adopt a dynamic capabilities approach to supply chain management. Prior literature has shown dynamic capabilities can aid in developing strategic, structural, and operational flexibility. We extend this literature by showing that OAC and OL have an effect on SCF.

Keywords: Supply chain flexibility; environmental dynamism; absorptive capacity; organisational learning; survey. 


\section{Introduction}

Flexibility is widely acknowledged as being an important strategic capability (e.g. Krajewski et al., 2005; Eisenhardt et al., 2010). There is a rich history of research on flexibility in the operations and supply chain management literature, with much of the focus being at the firm level, on manufacturing flexibility (e.g. Slack, 1983, 1987). More recently, the focus has shifted to studying flexibility in a wider supply chain (SC) context (e.g. Stevenson and Spring, 2007; Blome et al., 2013). Supply Chain Flexibility (SCF) is broadly concerned with the ability to rapidly reconfigure key SC resources in an attempt to maintain competitiveness (Stevenson and Spring, 2009; Blome et al., 2013). It is considered a key competitive weapon in the current, dynamic environment (Gunasekaran et al., 2001; Vanpoucke et al., 2014).

Although conceptual definitions of SCF frequently refer to it as being a response to the environment (Rojo et al., 2016), empirical evidence on the relationship between the environment and SCF is limited (Yi et al., 2011; Kim et al., 2013). Recent research has generally begun to examine the link between the environment and SC strategies (Gligor, 2014; Kovach et al., 2015; Gligor et al., 2015), but there is a need for further research on the alignment between environmental conditions and particular SC strategies, including flexibility. Since developing SCF takes time, consumes resources, and can be risky (Fantazy et al., 2009; He et al., 2012), firms need to know when it is an advantageous strategy. Although there are other dimensions to the environment (e.g. munificence and complexity), dynamism - which incorporates unpredictability and instability (Kovach et al., 2015) - has been argued to have the most influence on firm decisions and performance (Keats and Hitt, 1988). Therefore, part of the focus of this paper is on the alignment between the environment and SC strategy through the relationship between environmental dynamism and SCF.

Although the benefits of a flexible SC strategy are generally known (e.g. Aprile et al., 2005; Swink et al., 2005), the antecedents of SCF are less well understood (Swafford et al., 2006; Blome et al., 2013). In particular, there is a need for further research on how firms can build a flexible SC strategy (Blome et al., 2014). SCF fosters alignment with the environment and "alignment implies that the firm must have the potential to learn, unlearn, or relearn" (Fiol and Lyles, 1985: p. 804). Thus, we propose that one potential approach to facilitating SCF is through dynamic capabilities, specifically those related to learning and knowledge processes (e.g. operational absorptive capacity and organisational learning). According to Gupta and Govindarajan 
(2000), knowledge is a significant source of competitive advantage in supply chain management (SCM). Furthermore, dynamic capabilities have the ability to change resources, routines, and competences (Easterby-Smith and Prieto, 2008). The literature has shown that dynamic capabilities can aid in developing strategic, structural, and operational flexibility (e.g. Barrales-Molina et al., 2013), but it is unknown whether this extends to the level of the SC. Meanwhile, Operational Absorptive Capacity (OAC) and Organisational Learning (OL) have only recently begun to receive attention in the context of SCM and have rarely been studied from a dynamic capabilities perspective (Manuj et al., 2014; Dobrzykowski et al., 2015). Trkman et al. (2015) suggested that dynamic capabilities must be incorporated into the study of SCM, and it is argued that they can play a role in developing SCF. Therefore, a second focus of this paper is on how to achieve SCF through its relationship with both OAC and OL.

Against this backdrop, we seek to address the following research question through a survey of 302 Spanish manufacturing firms:

What is the relationship between supply chain flexibility and environmental dynamism? And what role do dynamic capabilities (operational absorptive capacity and organisational learning) play in developing supply chain flexibility?

The underlying assumption of our research is that the capabilities developed by the firm have the potential to influence the firm's ability to manage its SC.

The remainder of this paper is organised as follows. Section 2 presents the theoretical background, reviewing the relevant literature to develop hypotheses. Section 3 then presents the research method, including data collection and analysis procedures. Section 4 uses the data to test each hypothesis, followed by a discussion. The paper then concludes with Section 5, which includes implications for research and practice.

\section{Theoretical Background}

We follow the approach defined by Whetten et al. (2009) and used by Patel et al. (2012) in order to explain the proposed relationships. This approach consists of horizontal theory borrowing across different contexts and vertical theory borrowing across different levels. This allows us to deploy theory from the strategic management literature to explain operations and SC relationships, as advocated by Ketchen and Guinipero (2004). For example, we horizontally borrow the concept of absorptive 
capacity that has been used, for example, in a strategic management context. We also vertically borrow the explanation of why OAC and OL should enable SCF by employing arguments originally developed for a different level of analysis (strategic, structural, and operational) to explain relationships at the SC level.

\subsection{Environmental Dynamism}

The two main characteristics of environmental dynamism are unpredictability and instability (Kovach et al., 2015). Miller et al. (2006: p. 99) defined unpredictability as "the lack of regularity in the pattern of change in the environment" and instability as "the extent to which an environment exhibits change". Therefore, dynamism reflects the rate and volume or magnitude of environmental changes (Rosenzweig, 2009; Azadegan et al., 2013). It includes, for example, changes as a result of technology, variations in customer preferences, and fluctuations in product demand and material supply (Wang et al., 2011). Research has found that product variety and demand volatility are greater in highly dynamic environments and when product life cycles are shorter (Mitchell et al., 2011). This means that firms have to regularly adjust their SC operations to deal with upstream and downstream uncertainties (Bozarth et al., 2009).

\subsection{Operational Absorptive Capacity (OAC) and Organisational Learning (OL)}

The dynamic capabilities perspective - an extension of the resource-based view argues that each firm has its own set of resources and capabilities that explain its competitive position and long-term performance (Teece et al., 1997). According to Barreto (2010: p.271), dynamic capabilities refer to a "firm's potential to systematically solve problems, formed by its propensity to sense opportunities and threats, to make timely and market-oriented decisions and to change its resource base". Two key constructs in the dynamic capabilities literature are OAC and OL (Zahra and George, 2002; García-Morales et al., 2007), as discussed below.

\subsubsection{Operational Absorptive Capacity: OAC}

Absorptive capacity is defined as a firm's ability to "synthesize and apply current and acquired knowledge" (Kogut and Zander, 1992: p. 384) and to "recognize the value of new, external information, assimilate it, and apply it to commercial ends" (Cohen and Levinthal, 1990: p.129). We adopt the more specific term "operational absorptive capacity" that was proposed by Patel et al. (2012) and, building on Cohen and Levinthal (1990), defined as “the ability of a firm's operational units to acquire, assimilate, 
transform and exploit knowledge from the operations' management" (Patel et al., 2012: p. 202). But we also broaden out this concept to include the SC department and related knowledge. OAC thus involves the acquisition, assimilation, transformation, and exploitation of operations and SC knowledge. Until now, little empirical research has been conducted on OAC (Malhotra et al., 2005; Patel et al., 2012). Our study will thus complement prior research and extend it to the SC field of study.

\subsubsection{Organisational Learning: $O L$}

OL is important when adapting to new realities (Vanpoucke et al., 2014) yet there is some debate regarding whether OL is a specific capability in itself or rather a process that generates dynamic capabilities (Barrales-Molina et al., 2013). We follow GarcíaMorales et al. (2007: p.528) by considering it a specific capability "by which the knowledge created by individuals is increased in an organized fashion and is transformed into part of the knowledge system of the organization". OAC and OL are complementary capabilities (García-Morales et al., 2007) because the ability to absorb and manage knowledge is associated with a firm's continuous effort to engage in learning (Zahra and George, 2002). It must however be noted that, in combining operational absorptive capacity and organisational learning, we pool together dynamic capabilities related to two different subjects of learning and types of knowledge: OAC is attributed to operations and SC departments and focuses on operational and SC knowledge whereas OL is a characteristic of the whole firm and makes reference to general organisational and managerial knowledge. Prior studies have typically focused on either operational or organisational types (Malhotra et al., 2005; García-Morales et al., 2006; Patel et al., 2012) while we examine if both subjects of learning and types of knowledge are important to SCF.

\subsection{Relationship between Environmental Dynamism, OAC and OL}

Both theoretical and empirical research has been hindered by the heterogeneous and markedly idiosyncratic nature of dynamic capabilities (Teece, 2007; Barrales-Molina et al., 2013). Research has largely focused on studying the antecedents or factors that influence the generation of dynamic capabilities and on their effects or results (Barreto, 2010). In particular, researchers have attempted to identify and analyse the commonalities or common traits in dynamic capabilities - dynamic capabilities as diverse as alliance development (Lee et al., 2011), organisational learning (GarciaMorales et al., 2007), alliance and acquisition management (Zollo and Singh, 2004), 
new product development (Eisenhardt and Martin, 2000), absorptive capacity (Cohen and Levinthal, 1990), operational absorptive capacity (Patel et al., 2012), and so on. This literature argues that, despite their heterogeneity, both the antecedents and effects are common to any dynamic capability (Barreto, 2010). In this line of work, authors have identified the internal and external factors that influence the generation of dynamic capabilities. Primarily, these are environmental conditions (Teece, 2007), experience accumulation, knowledge articulation, and knowledge codification (Zollo and Winter, 2002).

With regards to the environment, Teece (2007: p. 1325) explained that: "Within the dynamic capabilities framework, the environmental context recognized for analytical purposes is the business ecosystem - the community of organizations, institutions and individuals that impact the enterprise". Thus, environmental dynamism as a factor that influences the generation of dynamic capabilities refers to the macro level of the environment, according to the classification proposed by Flynn et al. (2016).

Although there is some prior research on the environment and dynamic capabilities, the extant literature has two key shortcomings. First, it is largely theoretical, and there is no consensus among the different diverging research streams. Second, hardly any empirical research relates the environment to specific dynamic capabilities (Barreto, 2010). Our study attempts to fill this gap by empirically analysing the relationship between environmental dynamism and two specific dynamic capabilities, OAC and OL, based on theoretical support provided by the literature.

Despite the important role that is attributed to the environment in the literature on dynamic capabilities (Teece et al., 1997), we find three different perspectives on the relationship between the environment and dynamic capabilities. First, there are papers that view dynamic capabilities as being linked to relatively stable environments. For example, Eisenhardt and Martin (2000) argued that, in relatively stable environments, a company will benefit from developing dynamic capabilities; whereas, in highly volatile markets, dynamic capabilities produce unpredictable results. The authors argued that dynamic capabilities permit predictable outcomes when changes in the environment are moderate since these capabilities are based on a firm's prior tacit knowledge and are thus detailed, complex analytic processes. In contrast, in highly dynamic environments, firms cannot rely on prior knowledge. They will thus find it much more difficult to develop patterns of behaviour that serve to respond to any type of contingency. In fact, it was claimed that prior knowledge can sometimes even make it harder to develop 
dynamic capabilities since this knowledge could lead to overgeneralisation in solving problems.

Second, there are opposing papers that link dynamic capabilities to highly dynamic environments. For example, Teece et al. (1997) argued that, in turbulent environments, a firm must rely on the ability to create, maintain, and renew its bases of competitive advantage. In fact, according to Cao et al. (2012), the value of dynamic capabilities lies in how they enable organisations to continually monitor and renew their functional competencies in response to a rapidly changing competitive environment. In line with this argument, Zollo and Winter (2002) and Teece (2007) explained that dynamic capabilities are completely useless in stable environments and that these mechanisms will not be developed in the absence of dynamism because they are extremely costly. Further, O'Connor (2008) asserted that a highly dynamic environment is a necessary condition for generating dynamic capabilities. This second view on the relationship between the environment and dynamic capabilities is based on the argument that dynamism imposes continual imbalances on a firm (Bogner and Barr, 2000) that require it to develop an ability to routinely respond to contingencies without being destabilized (Sánchez, 1995). To avoid being destabilized internally by uncontrollable external circumstances, organisations must develop a set of higher-order patterns of behaviour or routines (so-called dynamic capabilities) that enable them to systematically reconfigure their lower-order operating routines in response to unexpected changes (Zollo and Winter, 2002).

Finally, there are papers that view dynamic capabilities as being important for dealing with in-house changes. For example, Zahra et al. (2006) stressed that firms need dynamic capabilities for responding to internal variation, regardless of the environment. Such authors believe that it is a mistake to tie the development of dynamic capabilities to environmental conditions since the need to reconfigure and renew organisational routines can come from within the firm itself (e.g. when a young firm begins to grow and faces the challenge of reconfiguring its processes to maintain efficiency).

The above disagreement prompted Barreto (2010) to call for more research into the kinds of environments in which dynamic capabilities are most relevant. The dominant paradigm however from both a theoretical and an empirical perspective is that dynamic capabilities are required and developed in more volatile markets. From a theoretical perspective, the approach proposed by Teece (2007) predominates as it is the foundation upon which the most recent studies have attempted to establish a classification for 
dynamic capabilities based on the dynamism and unpredictability of the environment as perceived by a manager (e.g. Ambrosini et al., 2009). Ambrosini et al. (2009) thus assumed that dynamism is a necessary condition for the development of dynamic capabilities and that the type of capability a firm develops will depend on the level of dynamism detected. From an empirical perspective, we cite Barrales-Molina et al. (2013), who showed that one commonality present in any type of dynamic capability is a dynamic environment. In other words, it has been shown that only firms that perceive a high level of dynamism promote and develop dynamic capabilities. The authors interpreted this finding to mean that firms do not become involved in the process of generating dynamic capabilities unless they perceive it as being strictly required by the environment in which they are located, as the process is complex and costly. More recently, Wilhelm et al. (2015) showed that dynamic capabilities have little value in stable environments since stable environments hardly provide firms with the possibility of improving operating routines. It is thus the second of the views above that is adopted in this study while the specific dynamic capabilities introduced - OAC and OL - may explain why some firms are able to develop more effective responses to environmental dynamism than others (Patel et al., 2012; Kristal et al., 2010). Both OAC and OL are embedded in learning and knowledge processes, and it has been suggested that they allow organisations to understand, interpret, and create accurate responses to environmental conditions (García-Morales et al., 2006).

This discussion leads to our first pair of hypotheses:

H1a: Environmental dynamism is positively associated with Operational Absorptive Capacity

H1b: Environmental dynamism is positively associated with Organisational Learning

\subsection{Supply Chain Flexibility (SCF)}

There are many different definitions of SCF in the literature (e.g. Duclos et al., 2003; Lummus et al., 2005; Martínez-Sánchez and Pérez-Pérez, 2005), but all refer in some way to it being an ability of the SC function to react to changes in the environment. Most definitions however share two problems: (i) they confuse the dimensions inherent in manufacturing flexibility with those in SCF, making it harder to establish a clear distinction between manufacturing flexibility and SCF; and, (ii) they lack a measurement scale that operationalises their conceptualisation (Stevenson and Spring, 2007). 
We thus follow the model proposed by Moon et al. (2012), which resolved the aforementioned problems. The authors posited that SCF is a construct composed of the following dimensions: sourcing flexibility, i.e. the availability of materials and services and the ability to purchase them according to changing needs; operating system flexibility, i.e. the capability to provide products with a wide variety of characteristics, combinations, and volumes to satisfy multiple customer specifications; distribution flexibility, i.e. a firm's ability to manage its distributors, warehouses, loading capabilities, and other distribution installations effectively and efficiently; and, information systems flexibility, i.e. the ability of a firm's information systems to adapt to changing market circumstances, especially in situations of unexpected misfit.

A flexible SC can be employed as a reactive capability, but it can also perform a strategic role (Rojo et al., 2016). In uncertain environments, firms can develop a competitive advantage by using flexibility to handle uncertainty and dynamism better than the competition (Stevenson and Spring, 2007). The literature is in nearly unanimous agreement on the positive effect of SCF on organisational performance (e.g. Aprile et al., 2005; Martínez-Sánchez and Pérez-Pérez, 2005; Swink et al., 2005; Blome et al., 2013), but the mechanisms underlying this capability are severely underexplored. It is argued here that research should now focus on these mechanisms for developing SCF.

\subsection{Dynamic Capabilities Framework and its Relationship with SCF}

The dynamic capabilities perspective argues that each firm has its own set of resources and capabilities that explain its competitive position and long-term performance (Barney, 1991). According to Barreto (2010: p.271), dynamic capabilities refer to "the firm's potential to systematically solve problems, formed by its propensity to sense opportunities and threats, to make timely and market-oriented decisions and to change its resource base". From this definition, it follows that a firm that possesses dynamic capabilities is able to change its resource base, reallocating the resources invested in its supply chain according to market demands. This has a clear resonance with the concept of SCF. In particular, it becomes easier for a firm to change the functional structure of facilities that are related to the supply chain (e.g. warehousing, loading capacity, and other logistics facilities), to switch delivery modes, and to change distributors and providers (Swafford et al., 2006; Moon et al., 2012). Further, a firm that is able to sense opportunities will find it easier to quickly respond to the market and take advantage of 
its environment. Finally, making timely decisions enables the creation of products and services that match customer characteristics, which is an important aspect of SCF (Moon et al., 2012); and minimises the effects of supply interruptions or sudden changes in market demands.

Previous research has established that there is a hierarchy of firm capabilities made up of: (i) zero-level capabilities, ordinary capabilities or operating routines that are oriented towards the operational functioning of the organisation; and, (ii) higher-level capabilities, substantive capabilities or dynamic capabilities oriented towards the modification of operational routines (Zollo and Winter, 2002; Winter, 2003; Zahra et al., 2006). The relationships between dynamic and operational capabilities are wellestablished theoretically, whereby operational capabilities are the visible outcome of dynamic capabilities (Easterby-Smith and Prieto, 2008). But there has been a need to empirically confirm this relationship in the context of specific operational capabilities (Easterby-Smith and Prieto, 2008). Barrales-Molina et al. (2013) have since shown empirically that strategic flexibility, structural flexibility, and operational flexibility are outcomes that can be derived from dynamic capabilities. Of these three, structural flexibility is closest in definition to SCF (Karim, 2006). Structural flexibility has been defined as "the ability of the firm to adapt its organizational structure to new conditions, such as creating multi-functional teams or purchasing components" (Barrales-Molina et al., 2013: p.577). Managing SCF is however arguably more difficult because it is necessary to reconfigure resources and assets across different firms with different operating routines.

It is argued that some particular dynamic capabilities might enable an operational capability such as SCF (Kristal et al., 2010). More specifically, we consider that OAC and OL will enable SCF by diminishing a lack of familiarity with the routines and resources of supply and distribution partners. To the best of our knowledge, the role of dynamic capabilities in enabling SCF has not been determined. The following subsection focuses on how OAC and OL might influence SCF.

\subsubsection{The Impact of $O A C$ and $O L$ on $S C F$}

We briefly argued above that OAC and OL may help firms to develop SCF by reducing a lack of familiarity with the routines and resources of SC partners. We expect these dynamic capabilities to help explain how firms renew and realign their supply chain routines to adapt to environmental changes (Patel et al., 2012), providing a basis for 
commonly directed efforts between SC partners and enabling SCF; however, empirical evidence is needed to confirm this. Within an organisation, an agreed vision enables coordination (Gioia and Thomas, 1996); but each firm in the SC has its own organisational culture and know-how, and has, e.g. different logistics procedures, strategies, technologies, and management practices. This makes it difficult to obtain a shared view on quality, speed, etc., thereby potentially jeopardising flexibility. It therefore becomes important that an organisation is able to understand how its partners think and is able to interpret the environment.

OAC and OL are dynamic capabilities that refer to two different subjects of learning and types of knowledge, and that operate in different ways. Our study thus includes capabilities at different levels, which is an approach supported by a recent literature review performed by $\mathrm{Yu}$ et al. (2015: p.194), which affirmed that "the internal dimensions of SCF arise at the shop and company level, while the external dimensions arise at the chain level". This distinction suggests that developing SCF requires the possession of capabilities at both the operational and organisational levels, and that the former are associated with inter-organisational SC processes and the latter with intraorganisational SC processes.

We can expect OAC to affect SCF by improving inter-organisational SC processes, since the knowledge acquired via OAC permits the firm to develop a deep understanding of customers' needs and to organise suppliers' and distributors' resources so that customers' needs are attended, which is essential to the development of a flexible SC, aligned with changes in the environment (Dobrzykowski et al., 2015). Dobrzykowski et al. (2015) explained and tested empirically whether absorptive capacity at the SC level especially affects the configuration of suppliers' and distributors' portfolios, as well as the coordination of goods flows with both suppliers and distributors. Changes in supplier and distributor portfolios were used to refer to better selections from these parties based on quality performance, lead times, and delivery times.

The value of absorptive capacity lies in the notion that existing knowledge is often needed to acquire new knowledge, and that new knowledge also enhances existing knowledge (Katila and Ahuja, 2002). It is claimed that firms with absorptive capacity are not only more sensitive to any opportunities that are presented; they are also more proactive in exploring and exploiting these opportunities by combining internal and external resources (Cohen and Levinthal, 1990). OAC permits the firm to become 
familiar with the culture of other firms in its SC, their working habits, and their technological sophistication. In other words, it permits the firm to better understand the internal capabilities of its partners, which enables the firm to combine its partners' know-how with its own to achieve better alignment with, and response to, its environment (Azadegan, 2011). Azadegan (2011) further argued that absorptive capacity in managing relationships with suppliers and distributors is a source of dual benefit. First, it increases the manufacturing firm's ability to recognize, understand and internalise its partners' innovation capability. And second, increased overlap in knowledge permits better interactions among the members of the SC, through which the firm improves its knowledge of the other members of the SC. A greater overlap has positive repercussions for inter-organisational routines and SC processes, facilitating the firm's adaptation to its environment. Thus, a firm with a high level of OAC should be able to identify and interpret changes in the operational environment; find appropriate responses to these changes; and adapt through the renewal, realignment, and reconfiguration of operational and SC routines. Cohen and Levinthal (1989) asserted that absorptive capacity enables firms to proactively respond to competitive environment changes, adapting their machining, labour and material arrangements.

We argue here that the benefits of absorptive capacity should extend to the level of the SC. Tu et al. (2006) demonstrated the positive effect of absorptive capacity on timebased manufacturing practices, which enable a firm to anticipate and respond effectively to rapid environmental changes. One time-based manufacturing practice is having dependable suppliers. This practice is closely related to the conceptual domain of SCF and leads to shorter manufacturing cycles, increasing flexibility (Tu et al., 2006). More recently, Gligor (2014) asserted firms that develop relationships with members of their SC are able to quickly meet their customers' ever-changing expectations. Underpinning the development of these relationships is OAC. It is only if a firm possesses OAC that it can take full advantage of interactions with SC partners and translate them into an accurate response to environmental changes. Similarly, the literature review by Dobrzykowski et al. (2015) found that absorptive capacity plays an important role in developing a responsive SC strategy. Thus, we consider OAC to be fundamental to developing SCF. Finally, OAC permits the firm to acquire knowledge and incorporate it in the form of new practices and routines in its relationships and processes with suppliers and distributors. This enables the firm to formulate responses aligned to 
changes in the environment in the form of rapid new product launches, lower commercialisation times, etc.

OL is described as an important part of being able to adapt to the environment $\left(\mathrm{O}^{\prime}\right.$ Reilly and Tushman, 2008); and this ability is affected by learning processes within a firm and between a firm and the wider SC (Vanpoucke et al., 2014). Prior literature has linked OL to an organisation's ability to adapt to its environment (García-Morales et al., 2006). Thus, OL should also help managers to adapt their SC to the environment. Learning in SCs can be stimulated, for example, by exchanging, analysing, and appropriately using information. Moreover, a lack of OL capacity in highly dynamic environments may explain why organisations become less effective at assimilating technology and practices that lead to competitive advantage (Huber, 1996). And, in accordance with Bessant et al. (2003), the competitive performance of an organisation's SC is argued to be dependent upon OL. Further, Hult et al. (2003) considered OL to be a strategic resource in SCM and found that OL has a positive effect on the cycle time of the SCM process.

We expect the effect of OL on SCF to occur through improvements in the intraorganisational processes of the SC since OL is an important internal factor and precursor of an organisation's process flexibility (Llorens et al., 2005). In fact, OL has been used so effectively to solve workflow problems and increase the flexibility of intra-organisational processes that it is a key ability for process innovation (Fang et al., 2016). Braunscheidel and Suresh (2009) also showed that OL improves the internal integration of SC processes, which in turn has a positive influence on their flexibility. This result is due to the fact that OL leads firms to actively question how their intraorganisational processes function and how well they are organised internally. Firms with a high level of OL are constantly questioning their current processes and seeking better forms of organisation, such as forming cross-functional teams, adopting a focus oriented towards process management, and improving process technology performance (Song and Di Benedetto, 2008). We can thus conjecture that the impact of OL on SCF will occur through the improvement of intra-organisational SC processes, whether through the application of innovative solutions, better management of these solutions, improved performance of process technology, or better integration of these processes. This evidence enables us to hypothesise that OL not only has an impact on organisational performance but also on SC performance, including SCF.

This discussion leads to our second pair of hypotheses: 
H2a: The higher the level of Operational Absorptive Capacity, the higher the level of Supply Chain Flexibility

H2b: The higher the level of Organisational Learning, the higher the level of Supply Chain Flexibility

The above suggests that both OAC and OL will contribute to improving SCF. Below we suggest that OAC will have a greater effect on SCF than OL. We hypothesise this because Loufrani-Fedida and Saglieto (2016: p. 79) showed that operational knowledge has a stronger effect at the operational level than other types of knowledge because it "is formalized in rules and procedures (methodologies, management processes, quality procedures, drafting of standard documents, tracking tools...) and this formalized knowledge serves as a cue for action". This stronger effect is due to a closer proximity between functional actors, which plays an important role in knowledge sharing. Meanwhile, Zappa and Robins (2016, p. 295) asserted that "units are more likely to retain knowledge acquired within their boundaries". Following this line of argumentation, we can expect that $\mathrm{OAC}$, predicated on operational knowledge, will have a greater effect on SCF than OL, which refers to more general organisational and managerial knowledge. In the case of the latter, personnel and knowledge are dispersed across different units, which can prevent or weaken the effect of OL on SCF (Zappa and Robins, 2016). Further, the more general the knowledge, the more likely it is that it may be excluded from the transfer process (Zander and Kogut, 1995). Similarly, Nonaka (1994) asserted that when knowledge is too heterogeneous it is more difficult to understand and integrate. OAC, on the other hand, refers to a particular type of knowledge specifically related to SCF, which should make it easier to integrate into SCF practices (Zappa and Robins, 2016). The authors also showed, through a case study, that the knowledge-search-transfer-integration process is stronger within the same unit than across different firm organisational units or departments.

This discussion leads to our third hypothesis:

H3: Operational Absorptive Capacity has a greater effect on Supply Chain Flexibility than Organisational Learning.

\subsection{Relationship between Environmental Dynamism and SCF}

The relationships previously proposed lead us to formulate our hypothesis on the mediating role of both OAC and OL on the relationship between environmental dynamism and SCF. It might be anticipated that there is a direct relationship between 
the environment and the level of flexibility, i.e. that the nature of the environment influences the level of flexibility that is required from an operation or SC. Indeed, it has been argued by several authors that both a firm and its supply chain should be more flexible when operating in highly dynamic environments (e.g. Martínez-Sánchez and Pérez-Pérez, 2005; Sebastiao and Golicic, 2008). However, the literature presents strong evidence that leads us to question whether environmental dynamism has a direct effect on SCF, suggesting the relationship between the two variables is more complex.

Pagell and Krause (1999), for example, tested the relationship between the environment and flexibility (operational and manufacturing) but found no empirical evidence to support the relationship. The best-performing firms in their study had the highest levels of manufacturing flexibility regardless of the degree of environmental dynamism. Further, Ward and Duray (2000) found that the relationship between the environment and flexibility level is indirect, mediated by a firm's competitive strategy. More recently, Patel et al. (2012) found that some firms are able to develop more effective responses to environmental dynamism than others. Finally, the findings of $\mathrm{Yu}$ et al. (2015) are particularly significant; their meta-analysis of 57 empirical articles found that environmental uncertainty drivers (e.g. task-related uncertainty, demand variation, technological complexity, and market impact) have no direct effect on SCF, whereas intra-organisational sources (including absorptive capacity) have direct effects on SCF. According to the contingency view, forms of fit with the environment include matching, moderation, mediation and gestalts (Venkatraman, 1989). Our model presents an alternative form of fit with the environment, founded on a more complex contingency focus with greater explanatory capability. It enables us to test and corroborate whether the effect of an antecedent variable (environmental dynamism) on a consequent (SCF) operates through multiple mechanisms (OAC and OL) that work simultaneously (Hayes, 2013) whereas the forms of fit previously presented do not permit either consideration or testing of multiple processes simultaneously. Furthermore, our model has greater explanatory power because although most effects and phenomena (including fit and alignment) operate through multiple mechanisms at once (Hayes, 2013) previous models have only taken one relationship or mechanism into account (Cao et al., 2012).

We adopt the perspective of Teece et al. (1997) who argued that, as dynamism increases, it becomes more difficult for a firm to adapt to the environment and that, in some cases, it may even lose its ability to adapt. In this context, firms can develop 
competitive advantage by combining and forming synergies between different firm capabilities (Ruiz-Moreno et al., 2009). Thus, it is argued here that OAC and OL may explain why some firms are more successful than others; and that these dynamic capabilities mediate the relationship between environmental dynamism and SCF. Our hypothesis is therefore:

H4: Operational Absorptive Capacity and Organisational Learning mediate the relationship between Environmental Dynamism and Supply Chain Flexibility

Constructing a mediation model requires hypothesising about the nature and strength of the indirect effects such that a decomposition effect can be evaluated that enables further understanding of our multiple mediator model (Hayes, 2013). Specific indirect effects represent the proportion of the total effect that works through a single intervening variable (Zhao et al., 2010). We thus propose that environmental dynamism is modelled as indirectly influencing SCF through OAC and OL such that the indirect effect of environmental dynamism on SCF through OAC refers to the alignment between the environment and SCF that occurs due to OAC. In parallel, the indirect effect of environmental dynamism on SCF through OL refers to the alignment between the environment and SCF that occurs due to OL. In other words, by modelling the indirect effects of environmental dynamism on SCF, we can theorise about how these capabilities help the firm to "convert" or "transmit" changes in the environment into the development of a flexible SC. We can expect OAC to be a better alignment mechanism than OL because: (i) the knowledge resulting from OAC enables greater functional integration (Ellegaard and Koch, 2012) due to its closer proximity to the operating system; and, (ii) OAC enables the creation of effective value for the firm from the stimuli it has found outside itself, generating results based on solution building (Zablith et al., 2016). In contrast, the transmission of dynamism in the environment to the development of a flexible SC via OL must be softer, as the greater distance between functions (Toon et al., 2016) - i.e. between the general managerial function and that of the SC - can weaken this indirect effect. Likewise, insofar as OL refers to managerial general knowledge, there is a risk that the transmission of knowledge from the environment to the SC will decontextualize that knowledge. In other words, that the transmission of the stimuli from the environment to the SC will result in broken or disconnected blocks of knowledge and information since a capability that fits a general 
context cannot be the most appropriate in the more specific context of the SC. Based on the arguments explained above, we propose our final hypothesis:

H5: The indirect effect of environmental dynamism on supply chain flexibility through OAC is significantly greater than the indirect effect of environmental dynamism on supply chain flexibility through OL.

The relationships to be empirically investigated are illustrated in the theoretical model in Figure 1.

\section{[Take in Figure 1]}

\section{Method}

\subsection{Survey Design and Sample}

A survey was conducted to gather specific information for our research. The questionnaire was developed following Moore and Benbasat's (1991) three-stage procedure. The constructs were defined and a pool of items was established for each construct. Four Q-sort rounds were performed to evaluate the scales' content validity; and the items were revised to improve clarity after each round. Changes did not result in final items that were substantially different from the originals. This procedure was repeated after purification of the scales. Further, the data was collected in a nonEnglish-speaking country, so Brislin's (1976) back-translation steps were followed.

Spanish manufacturing firms were established as the object of study. The population was obtained from the SABI 2014 database (Iberian Balance Sheet Analysis System), which is comprised of 45,166 firms. Only firms belonging to the manufacturing sector that provided complete data (e.g. correct telephone number), had non-cessation of activity, and had >10 workers were considered, leaving 2,517 firms. The survey was addressed to those responsible for the firm's SC, the purchasing manager, or the top manager. The data was obtained through computer-assisted telephone interviews (CATI) with a total of 302 valid responses obtained (12\%). The sampling error is $5.23 \%$, with a confidence level of $95 \%(\mathrm{Z}=1.96)$ for $\mathrm{p}=\mathrm{q}=0.5$. Following Hair et al. (2010), missing data $(<1 \%)$ was imputed using the predictive mean matching algorithm (Little, 1988). The characteristics of the sample appear in Table I.

[Take in Table I] 
Non-response bias was evaluated according to Fawcett et al. (2014). The mean values of the size variables for all firms were compared to the mean values of the firms that responded, and the values were similar $(p>0.05)$. Finally, ten industries are represented in the data, so differences based on industry sector were assessed - none were found $(p>0.05)$.

\subsection{Measures}

The measurement scales for the variables, as shown in Appendix A, were adapted from prior studies to ensure validity and reliability: environmental dynamism (Ward and Duray, 2000), OL (García-Morales et al., 2007), OAC (Patel et al., 2012), and SCF (Moon et al., 2012). The scale for OAC from Patel et al. (2012) was adapted to include SC knowledge and the SC department. All items were accompanied by a seven-point Likert scale (1=maximum disagreement; $7=$ maximum agreement).

\subsubsection{Exploratory Factor Analysis}

An exploratory factor analysis of principal components was performed using SPSS v.22 for each set of questions determined ex-ante to represent each construct. The items with loadings $>0.4$ on more than one construct or that loaded on a factor that made no sense were eliminated (items Acq2, Acq5, and Ex6). After all measurement instruments were defined, another factor analysis was performed to verify the results. The factors obtained were consistent with prior expectations.

\subsubsection{Confirmatory Factor Analysis}

The measurement model was evaluated using confirmatory factor analysis (CFA). Schumacker and Lomax (1996) recommended a two-step procedure: (1) evaluate the measurement model to ensure its fit (and confirm discriminant and convergent validity); and, (2) examine the full model to evaluate predictive validity. EQS v.6.2 software was used to evaluate the measurement model and the structural model. Since the multivariate normality test showed non-normality of the data (Mardia's coefficient=111.092; $\mathrm{t}$-value=44.614), the robust ML estimation method was applied.

The scales' reliability was evaluated using the composite reliability statistics (CR), average variance extracted (AVE), and Alpha Cronbach. All statistics calculated for CR took values $>0.7$, and the AVE statistics took values $>0.5$, as shown in Table II. The Alpha Cronbach coefficients measure the internal consistency of the constructs. Given the goal of this study and its use of scales from the literature, values must be $>0.8$ 
(Nunnally, 1978), as confirmed by Table II. Overall, these results show acceptable values for reliability and internal consistency of the scales.

\section{[Take in Table II]}

A CFA was also developed to demonstrate multidimensionality and goodness of fit of the two second-order constructs used in the model (OAC and SCF). The measurement model for the second-order constructs obtained acceptable fit indicators, as summarised in Table III.

\section{[Take in Table III]}

Discriminant validity was evaluated in accordance with Voorhees et al. (2016). First, the approach developed by Fornell and Larcker (1981), which involves comparing the square root of the AVE with the correlations between constructs, was used. The square root of the AVE appears on the main diagonal of Table IV and is greater than the correlations between constructs. This demonstrates the presence of discriminant validity between the constructs used in the model. Second, the HTMT ratio (Henseler et al., 2015) was calculated for each pair of constructs. As Table V shows, the HTMT ratio is $<0.85$ for each pair of constructs, also indicating the presence of discriminant validity. In demonstrating the discriminant validity of OL and OAC using two different procedures (Fornell-Larcker criterion and HTMT ratio), we follow the "holistic" approach proposed by Zhao and Anand (2009: p. 797) that permits us to consider variables related to knowledge transfer on two different levels - operational absorptive capacity and organisational learning - simultaneously.

\section{[Take in Tables IV\&V]}

\subsubsection{Common Method Bias}

The potential for common method bias was also evaluated by adopting a series of procedural measures before collecting the data (Podsakoff et al., 2003). Although respondents were aware that they were answering questions related to $\mathrm{SCM}$, learning mechanisms, and the environment, it is quite unlikely that they could have intuited the specific research model. If the research question is unknown, respondents are less able to manipulate their responses to satisfy expectations about the relationships assumed. Further, various response formats were used (e.g. 'not at all' to 'a lot', 'maximum disagreement' to 'maximum agreement', etc.), and the questions were not grouped by 
construct. The respondents' anonymity was also protected and a survey pre-test was performed to avoid ambiguity.

Statistical analysis of common method bias was also conducted based on Harman's one-factor test (Podsakoff and Organ, 1986), which showed that ten factors are present, only $25.733 \%$ of the variance is explained by the first factor, and that the remaining variance is explained through a balanced distribution across the other factors. This suggests common method bias is not an issue (Podsakoff and Organ, 1986). We also included a common latent variable in the model that was comprised of all items in the questionnaire (Podsakoff et al., 2003; Williams et al., 2003) and followed Liang et al. (2007) in comparing the substantial variance with the method variance. As shown in Table VI, the average substantively explained variance of the indicators is 0.666 while the average method-based variance is 0.017 , a ratio of approximately 39:1. Furthermore, most method factor loadings were not significant. Given the small magnitude of the method variance, we conclude that the method is unlikely to be a serious concern for this study.

\section{[Take in Table VI]}

\section{Results and Discussion}

\subsection{Fit of the Structural Model}

Evaluating the hypotheses requires the proposed model's global fit to be determined.

We follow the guidelines provided by Bollen and Long (1993, p.6) and Guide and Ketokivi (2015):

1. The model must fit a strong, substantial pre-existing theory. Only if the model is consistent with a significant theoretical corpus can it evaluate fit positively. Our model is grounded in a significant body of theoretical literature (see Section 2).

2. Calculate and evaluate the Chi-square. The Chi square value (Chi square $=389.881$; $\mathrm{p}<0.01)$ confirms the model fits the data well, as the observed and predicted covariance matrices are in agreement (Guide and Ketokivi, 2015).

3. Report multiple indices of global model fit. All indices produce acceptable values $(\mathrm{GFI}=0.905 ; \mathrm{RMSR}=0.053 ; \mathrm{RMSEA}=0.050 ; \mathrm{AGFI}=0.905 ; \mathrm{NFI}=0.926 ; \mathrm{NNFI}=0.934$; $\mathrm{IFI}=0.947 ; \mathrm{CFI}=0.947)$ indicating that the model fits the data well. 
4. Examine the model components. The following section and Figure 2 report the $\mathrm{R}^{2}$ value for each of the equations as well as the magnitude and significance of the estimated coefficients. Values consistent with the fit indices are presented.

5. Estimate several plausible alternative models to compare their fit indices. This uncovered no problems of endogeneity, as reported in Section 4.3 on model robustness.

In addition to the above, following Riedl et al. (2014), the statistical power of the SEM was calculated. A value of 0.83 (for $\varepsilon_{0}=0.05 ; \varepsilon_{\mathrm{a}}=0.08$ ) was obtained, which falls between 0.8 and 1 , thereby confirming the validity and reliability of the results.

\subsection{Hypothesis Testing: Results}

Figure 2 shows the estimation values of the standardised coefficients for the representative parameters of each hypothesis together with their respective significance levels. The results show that environmental dynamism is related to both $\mathrm{OAC}(\beta=0.553$; $\mathrm{t}=10.788 ; \mathrm{p}<0.05)$ and $\mathrm{OL}(\beta=0.538 ; \mathrm{t}=9.582 ; \mathrm{p}<0.05)$, thus empirically confirming Hypothesis 1a and Hypothesis $1 \mathrm{~b}$. This means environmental dynamism is associated with these two specific dynamic capabilities.

\section{[Take in Figure 2]}

The results also show that $\mathrm{OAC}(\beta=0.444 ; \mathrm{t}=6.372 ; \mathrm{p}<0.05)$ and $\mathrm{OL}(\beta=0.198$; $\mathrm{t}=3.015 ; \mathrm{p}<0.05$ ) have a positive and significant impact on SCF. This provides empirical evidence to confirm Hypothesis 2a and Hypothesis 2b. Although our results show that both OAC and OL have a positive and significant impact on SCF, the standardised coefficients suggest that OAC is a stronger enabler of SCF than OL. But to fully test Hypothesis 3, we must analyse the effect size of OAC on SCF and of OL on SCF (Cohen, 1988). To do so, we have calculated the effect size using the $\mathrm{f}^{2}$ statistic for each of the relationships. We obtained a value of $\mathrm{f}^{2}=0.372$ for the relationship between OAC and SCF and $\mathrm{f}^{2}=0.151$ for the relationship between OL and SCF. This statistic permits us to affirm that the effect size of OAC on SCF is stronger than that of OL on SCF. We can also describe, following Cohen's guidelines, that the effect size of OAC on SCF is large and that of OL on SCF is medium, thus confirming Hypothesis 3.

Hypothesis 4 stated that $\mathrm{OAC}$ and $\mathrm{OL}$ mediate the relationship between environmental dynamism and SCF. To test this, we followed Zhao et al. (2010). Thus, we estimated the direct, indirect and total effects of environmental dynamism upon 
SCF. We also calculated $95 \%$ bias-corrected confidence intervals using the multiple parallel mediators model with Preacher and Hayes' (2008) technique. Given that our model included multiple mediators (OAC and OL), the boot-strapping approach recommended by Preacher and Hayes (2008) was adopted with 5,000 bootstrap resamples. According to Zhao et al. (2010), a mediating effect is significant if the confidence interval for the indirect effect does not include zero. Table VII presents the results of this analysis, where the direct effect of environmental dynamism on SCF is significant $(\beta=0.111 ; \mathrm{t}=2.628 ; \mathrm{p}<0.05)$ as well as both indirect effects, i.e. through OAC $(\beta=0.245 ; \mathrm{t}=4.779 ; \mathrm{p}<0.05 ; \mathrm{CI}=0.1408-0.3493)$ and $\mathrm{OL}(\beta=0.106 ; \mathrm{t}=2.068 ; \mathrm{p}<0.05 ; \mathrm{CI}=$ 0.0570-0.2153). Thus, these dynamic capabilities partially mediate the relationship between environmental dynamism and SCF. This can be classified as complementary mediation (Zhao et al., 2010) since the direct and indirect effects have the same sign. Also note that, in evaluating Hypothesis 4, we found an unexpected direct effect between environmental dynamism and SCF.

Finally, Hypothesis 5 theorised that the indirect effect of environmental dynamism on SCF through OAC is greater than the indirect effect of environmental dynamism on SCF through OL. Preacher and Hayes' (2008) technique enabled us to test whether one indirect effect is statistically different from another through a formal test of the difference between the specific indirect effects. The result of this test is the following bootstrap confidence interval for pairwise comparisons between our two indirect effects (0.2669-0.3069). Since this confidence interval does not contain zero, it provides evidence that the two indirect effects are statistically different from each other. Further, since the effects are of the same sign, the indirect effect of environmental dynamism on SCF through OAC is significantly greater than the indirect effect of environmental dynamism on SCF through OL, thereby supporting Hypothesis 5.

\section{[Take in Table VII]}

\subsection{Test of Robustness}

A test of robustness was performed to ensure the model does not suffer from problems of endogeneity (Rojo et al., 2016). A first alternative model was estimated and its global fit compared. This model assumed that environmental dynamism influences SCF, which in turn influences OAC and OL. The estimation results for the first alternative model are given in Appendix B, Figure 3, and the model's respective fit indices are as follows: Chi-Square $=488.268 ; \quad \mathrm{p}<0.001 ; \quad$ GFI=0.847; $\quad$ RMSR $=0.089 ; \quad$ RMSEA=0.099; 
$\mathrm{AGFI}=0.802 ; \mathrm{NFI}=0.885 ; \mathrm{NNFI}=0.895 ; \mathrm{CFI}=0.910 ;$ and, $\mathrm{IFI}=0.910$. A second alternative model was also estimated, in which we proposed that the effect of OAC and OL on SCF is moderated by environmental dynamism. The estimation results for this model are given in Appendix B, Figure 4, and the model's respective fit indices are as follows: Chi-Square=425.978; p<0.001; GFI=0.854; RMSR=0.096; RMSEA=0.106; AGFI=0.818; NFI=0.887; NNFI=0.844; $\mathrm{CFI}=0.824$; and, IFI= 0.825. The alternative models present worse fit, thereby affirming that the original model provides a better explanation of the data.

\subsection{Discussion of Results}

Our empirical support for Hypothesis 1a and Hypothesis 1b means that firms develop higher levels of OAC and OL when environmental dynamism is greater. This sheds light on the much debated relationship between the environment and dynamic capabilities. Our results follow the school of thought that OAC and OL should be developed in dynamic environments; the greater the dynamism, the greater the development of these dynamic capabilities. This supports the majority of studies (e.g. Teece et al., 1997; Zollo and Winter, 2002; O'Connor, 2008) and contradicts those that link the generation of dynamic capabilities to stable environments (Eisenhardt and Martin, 2000) and those that deny that there is any relationship between the environment and the development of dynamic capabilities (Zahra et al., 2006). It also answers the call of Barreto (2010) for further research into the type of environment where dynamic capabilities are relevant. This result is especially important given that most of the debates about the relationship between the environment and the generation of dynamic capabilities are purely theoretical, without any empirical support (BarralesMolina et al., 2013).

The empirical support for Hypothesis $2 \mathrm{a}$ and Hypothesis $2 \mathrm{~b}$ is consistent with the broader literature on the hierarchy of capabilities, which states that dynamic capabilities are aimed at achieving operational capabilities (Zollo and Winter, 2002; Winter, 2003; Zahra et al., 2006). But we tested this theoretical framework with specific dynamic and operational capabilities (i.e. OAC, OL, and SCF), thereby answering the call of Easterby-Smith and Prieto (2008) concerning further research into this theoretical relationship for specific capabilities. The results show that the power of these dynamic capabilities extends to the SC, enabling a flexible SC strategy to be achieved. Prior studies have shown empirically that dynamic capabilities enable strategic, structural, 
and operational flexibility (e.g. Barrales-Molina et al., 2013). Hence, our study complements prior research and extends understanding on the effects of these dynamic capabilities to include SCF. Our results thus confirm that OAC is an antecedent of SCF, insofar as it contributes to the flexibility of inter-organisational processes in the SC, since OAC permits the firm to become familiar with its partners' culture and knowhow, and to combine this knowledge with its own to encourage a response aligned with the environment. This result follows the line of recent studies (e.g. Azadegan, 2011; Dobryzkowksi et al., 2015) that have begun to explore the role of absorptive capacity in SCM. Our results also support the role of OL in the development of a flexible SC, as confirmed by the empirical study of Braunscheidel and Suresh (2009), and they extend the results of Llorens et al. (2005), who showed that OL affects improvements in the flexibility of intra-organisational processes, to the SC context.

Support for Hypothesis 3 means that OAC is a stronger enabler of SCF than OL. $\mathrm{OAC}$ and $\mathrm{OL}$ are at different levels - operational and organisational. Most studies focus on one level or the other, whereas our study incorporates both, thereby responding to $\mathrm{Yu}$ et al. (2015). It was suggested that developing SCF requires the possession of capabilities at both the operational and organisational levels. Indeed, both OAC and OL have a positive and significant impact on SCF, but it has been shown that OAC is a stronger enabler of SCF than OL. This result is consistent with Zappa and Robins (2016) who found that units are more likely to retain knowledge acquired within their boundaries. The more specific and specialised the knowledge, the more effective it is.

Hypothesis 4 focused on mediation, with the findings demonstrating that OAC and OL partially mediate the relationship between environmental dynamism and SCF. We argue that it is only when possible mediation is taken into account that a phenomenon can be fully understood; and, by doing so, this result opens the black box into the relationship between the environment and SCF. It shows that as the environment becomes more dynamic, achieving a flexible SC depends on an organisation's ability to acquire, process, and share knowledge (i.e. OAC and OL). Meanwhile, the unexpected direct effect between environmental dynamism and SCF corroborates the results of Martinez-Sánchez and Pérez-Perez (2005), who found that a higher level of perceived environmental dynamism is positively related to SCF, as well as supporting the traditional view of flexibility, which considers it to be an adaptive response to the environment (Gerwin, 1993; Upton, 1995). Further, this finding also supports Das and Patel (2002) who estimated SCF by linking it to the degree of uncertainty experienced 
by a firm's manufacturing operation. This result however contradicts the meta-analysis performed by $\mathrm{Yu}$ et al. (2015), which did not find a direct relationship between environmental dynamism and SCF.

Finally, the results for Hypothesis 5 confirm that the indirect effect of environmental dynamism on SCF is greater through OAC than through OL. This provides greater understanding of the capabilities that are needed to align the SC with the environment and of the weight or relative importance of each capability. It therefore guides managers in determining what capabilities, tools, and routines they should develop for knowledge management (Zablith et al., 2016).

Overall, our findings provide empirical support for the premise that firms should develop SCF when operating in highly dynamic environments. Further, firms can achieve SCF through the development of specific dynamic capabilities; in particular, through OAC and OL.

\section{Conclusions}

Our paper now closes with the main theoretical and practical implications followed by the limitations of our work.

\subsection{Theoretical Contributions}

This study makes three particular contributions. First, it contributes to the literature on the relationship between the environment and dynamic capabilities. It has been shown that $\mathrm{OAC}$ and $\mathrm{OL}$ are associated with dynamic environments. This means it is only when managers perceive there to be a high level of dynamism that they decide to commit resources to developing these dynamic capabilities. This supports Teece et al. (1997) and O’Connor (2008) but contradicts Eisenhardt and Martin (2000) who linked the development of dynamic capabilities to relatively stable environments. Our findings also reinforce the arguments put forward by Zahra et al. (2006) and Barreto (2010) that dynamic capabilities are associated with an important opportunity cost, so only if the environment is perceived as being unpredictable and unstable should managers develop them. One possible explanation for why our findings contradict Eisenhardt and Martin (2000) is that we have focused on capabilities that are embedded in learning and knowledge processes, and dynamic environments are "one of the main elements influencing learning by providing, evaluating, and promoting learning process[es] and [the] level of learning" (García-Morales et al., 2006: p.26). 
Second, it contributes to understanding on how dynamic capabilities shape SCF. Vertical borrowing (Whetten et al., 2009) of the explanation of why OAC and OL should lead to SCF allowed us to successfully examine the transferability of strategic concepts such as dynamic capabilities to the functional level or context of SCM. In doing so, we have answered the call of Ketchen and Guinipero (2004) to test strategic management theories in an operations and SC context. Our theoretical model could be applied to other types of dynamic capabilities that are embedded in learning and knowledge processes in the area of SCM. Our findings on how OAC and OL shape SCF also speak to the broader dynamic capabilities literature, offering evidence on their importance to SCM. Prior SCM work on OAC and OL is scarce and has been largely exploratory (Manuj et al., 2014; Dobrzykowski et al., 2015; Trkman et al., 2015). In contrast, our research is confirmatory, supporting previous studies that have stressed the importance of these dynamic capabilities to SCM.

Third, it contributes to the literature on the relationship between the environment and SCF. All theoretical definitions of SCF make reference to adaptation to the environment (Rojo et al., 2016), but this relationship has hardly been tested (Martínez-Sánchez and Pérez-Pérez, 2005). We have found that this relationship is partially mediated by OAC and OL, which means dynamism has a positive and direct impact on SCF. This supports Martínez-Sánchez and Pérez-Pérez (2005); but we also find that this relationship is more complex, because dynamism enhances SCF in the presence of OAC and OL. Following Teece et al. (1997), as dynamism increases, it becomes more difficult for a firm to adapt to the environment, meaning it needs to combine $\mathrm{OAC}$ and $\mathrm{OL}$ in order to deal with the environment and develop SCF.

\subsection{Practical Implications}

Managers should invest time and resources in developing OAC and OL when they perceive there to be higher levels of environmental dynamism, i.e. when the environment becomes increasingly unstable and unpredictable. Therefore, unlike some prior studies (e.g. Pagell and Krause, 1999), we do not suggest managers develop SCF regardless of the degree of environmental dynamism as investments in SCF incur both costs and risks for the firm (Fantazy et al., 2009; He et al., 2012). Further, developing dynamic capabilities unnecessarily can damage firm performance (Zahra et al., 2006). In practical terms, this means that understanding of the environment is critical 
(Barrales-Molina et al., 2013); hence, managers should endeavour to obtain an accurate picture of their environment so they can determine when to develop SCF.

Our findings inform managers that SCF can be developed through OAC and OL. Therefore, where necessary, managers should make investments in the acquisition, assimilation, and transformation of operational and organisational knowledge. Since knowledge-based resources (e.g. personnel, expertise, and research) can be scarce, managers should be aware that OAC is a stronger enabler of SCF than OL. Hence, it is particularly important that managers of the operations and SC department(s) facilitate interactions and communications, formal and informal, with other departments, customers, suppliers, distributors, etc. to obtain, record, and store new knowledge and to assimilate it with current knowledge (Patel et al., 2012).

Finally, it is important to stress that OAC and OL are not only enablers of SCF they also contribute to the alignment of SCF with the environment. This has been demonstrated through their mediating role and means that developing these capabilities helps firms overcome a mismatch between their SCF strategy and the environment. Further, OAC and OL provide firms with the mechanisms to adapt in dynamic environments by means of SCF. Thus, they offer an explanation for why some firms are able to develop more effective responses to dynamic environments than others. In practical terms, this means that if a firm does not have managers and employees (especially in operations and SC roles) that are able to learn from cross-functional and external initiatives, it will struggle to align SCF with the environment. Thus, it is important to motivate and incentivise managers to learn and to develop a culture that recognises, evaluates, acquires, shares, and implements new knowledge.

\subsection{Limitations and Future Research}

Our study measured SCF based on the perceptions of one manager from each firm. Further, although we asked respondents to answer questions from the perspective of their most important SC, clearly dyadic or triadic data would better represent the essence of the SC (Gligor et al., 2015). Our data is also cross-sectional, which makes it difficult to empirically test causality. When evaluating SCF with cross-sectional data, there is a risk of analysing a temporary situation in the organisation and not its capability for flexibility over time. Hence, future research could, where possible, collect longitudinal data on SCF. Finally, we have shown that OAC and OL mediate the relationship between environmental dynamism and SCF, but there may of course be 
other variables that mediate this relationship. Future research could therefore explore whether other dynamic capabilities, including innovation and ambidexterity (Kristal et al., 2010), also act as mediating variables.

\section{References}

Aprile, D., Garavelli, A.C. and Giannoccaro, I. (2005), "Operations planning and flexibility in a supply chain”, Production Planning \& Control, Vol.16 No.1, pp.21-31.

Ambrosini, V., Bowman, C. and Collier, N. (2009), "Dynamic capabilities: an exploration of how firms renew their resource base”, British Journal of Management, Vol.20 No.s1, pp. S9-S24.

Azadegan, A. (2011), "Benefiting from supplier operational innovativeness: the influence of supplier evaluations and absorptive capacity", Journal of Supply Chain Management, Vol.47No.2, pp.4964.

Azadegan, A., Pankaj,P., Abouzar, Z. and Linderman, K. (2013), "The effect of environmental complexity and environmental dynamism on lean practices", Journal of Supply Chain Management, Vol.31 No.4, pp.193-212.

Barney, J.B. (1991), "Firm resources and sustained competitive advantage", Journal of Management, Vol.17No.1, pp.99-120.

Barrales-Molina, V., Bustinza, O.F. and Gutiérrez-Gutiérrez, L.J. (2013), "Explaining the causes and effects of dynamic capabilities generation: A multiple-indicator multiple-cause modelling approach", British Journal of Management, Vol.24 No.4, pp.571-591.

Barreto, I. (2010), "Dynamic capabilities: a review of past research and an agenda for the future", Journal of Management, Vol.36 No.1, pp.256-280.

Besant, J., Kaplinsky, R. and Lamming, R. (2003), "Putting supply chain learning into practice", International Journal of Operations \& Production Management, Vol.23 No.2, pp.167-184.

Blome, C., Schoenherr, T. and Rexhausen, D. (2013), “Antecedents and enablers of supply chain agility and its effect on performance: a dynamic capabilities perspective", International Journal of Production Research, Vol. 51 No.4, pp. 1295-1318.

Blome, C., Schoenherr, T. and Eckstein, D. (2014), "The impact of knowledge transfer and complexity on supply chain flexibility: A knowledge-based view", International Journal of Production Economics, Vol. 147 Part.B, pp. 307-316.

Bollen, K.A. and Long, J.S. (1993), Testing structural equation models, Sage, Newbury Park.

Bogner, W.C. and Barr, P.S. (2000), "Making sense in hypercompetitive environments: a cognitive explanation for the persistence of high velocity competition", Organization Science, Vol.11 No.2, pp.212-226.

Bozarth, C.C., Warsing, D.P., Flynn, B.B. and Flynn, E.J. (2009), "The impact of supply chain complexity on manufacturing plant performance", Journal of Operations Management, Vol.27 No.1, pp. 78-93. 
Braunscheidel, M.J. and Suresh, N.C.(2009), "The organizational antecedents of a firm's supply chain agility for risk mitigation and response", Journal of Operations Management, Vol.27No.2, pp.119-140.

Brislin, R.W. (1976), "Comparative research methodology: Cross Cultural studies", International Journal of Psychology, Vol.11 No.3, pp. 215-229.

Cao, Q., Baker, J. And Hoffman, J.J. (2012), “The role of competitive environment in studies of strategic alignment: a meta-analysis", International Journal of Production Research, Vol.50 No.2, pp.567-580.

Cohen, J.E. (1988), Statistical power analysis for the behavioral sciences, Lawrence Erlbaum Associates, NJ.

Cohen, W.M. and Levinthal, D.A. (1989), "Innovation and learning-The two faces of R\&D", Economic Journal, Vol.99 No.397, pp.569-597.

Cohen, W.M. and Levinthal, D.A. (1990), "Absorptive capacity: a new perspective on learning and innovation", Administrative Science Quarterly, Vol.35 No.1, pp.128-152.

Das, S.K. and Patel, P. (2002), "An Audit Tool for Determining Flexibility Requirements in a Manufacturing Facility", Integrated Manufacturing Systems, Vol. 13 No. 4, pp. 264-274.

Dobrzykowski, D.D., Leuschner, R., Hong, P.C. and Roh, J.J. (2015), "Examining absorptive capacity in supply chains: linking responsive strategy and firm performance", Journal of Supply Chain Management, Vol.51 No.4, pp.3-28.

Duclos, L.K., Vokurka, R.J. and Lummus, R.R. (2003), "A Conceptual Model of Supply Chain Flexibility", Industrial Management \& Data Systems, Vol. 103 No.6, pp. 446-456.

Easterby-Smith, M. and Prieto, I.M. (2008), "Dynamic capabilities and knowledge management: an integrative role of learning?”, British Journal of Management, Vol.19 No.3, pp. 235-249.

Eisenhardt, K.M., Furr, N.R. and Bingham, C.B. (2010), "CROSSROADS-Microfoundations of performance: Balancing Efficiency and Flexibility in Dynamic Environments", Organization Science, Vol. 21, No.6, pp.1263-1273.

Eisenhardt, K.M. and Martin, J.A. (2000), “Dynamic capabilities: what are they?",Strategic Management Journal, Vol.21 No.10-11, pp.1105-1121.

Ellegaard, C. and Koch, C. (2012), "The effects of low internal integration between purchasing and operations on suppliers'resource mobilization", Journal of Purchasing and Supply Management, Vol.18No.3, pp.148-158.

Fang, E.A., Li, X. and Lu, J. (2016), "Effects of organizational learning on process technology and operations performance in mass customizers", International Journal of Production Economics, Vol.174, pp.68-75.

Fantazy, K.A., Kumar, V. and Kumar, U. (2009),“An Empirical Study of the Relationships among Strategy, Flexibility and Performance in the Supply Chain Context." Supply Chain Management: An International Journal, Vol. 14 No. 3, pp.177-188. 
Fawcett, S.E., Waller, M.A., Miller, J.W., Schwieterman, M.A., Hazen, B.T. and Overstreet, R.E. (2014), "A Trail Guide to Publishing Success: Tips on Writing Influential Conceptual, Qualitative, and Survey Research", Journal of Business Logistics, Vol. 35 No. 1, pp.1-16.

Flynn, B.B., Koufteros, X. and Li, G. (2016), "On theory in supply chain uncertainty and its implications for supply chain integration", Journal of Supply Chain Management, Vol. 52 No.3, pp. 3-27.

Fiol, C. M. and Lyles, M.A. (1985), "Organizational Learning”, Academy of Management Review, Vol.10 No.4, pp. 803-813

Fornell,C. and Larcker, D.F. (1981),"Evaluating structural equation models with unobservable variables and measurement error", Journal of Marketing Research, Vol. 43 No. February, pp. 3950.

García-Morales, V.J., Llorens-Montes, F.J. and Verdú-Jover, A.J. (2006), "Antecedents and consequences of organizational innovation and organizational learning in entrepreneurship", Industrial Management \& Data Systems, Vol. 106 No.1/2, pp.21-42.

García-Morales, V.J., Ruiz-Moreno, A. and Llorens-Montes, F.J. (2007), "Effects of Technology absorptive capacity and Technology proactivity on organizational learning, innovation and performance: An empirical examination”, Technology Analysis\& Strategic Management, Vol.19 No.4, pp.527-558.

Gerwin, D. (1993), "Manufacturing flexibility: a strategic perspective", Management Science, Vol. 39 No.4, pp. 395-410.

Gioia, D.A. and Thomas, J.B. (1996), "Identity, image, and issue interpretation: Sensemaking during strategic change in academia”, Administrative Science Quarterly, Vol. 41 No.3, pp. 370 - 403.

Gligor, D.M. (2014), “A cross-disciplinary examination of firm orientations performance outcomes: the role of supply chain flexibility", Journal of Business Logistics, Vol.35 No.4, pp. 281-298.

Gligor, D.M., Esmark, C.L. and Holcomb, M.C. (2015), "Performance outcomes of supply chain agility: when should you be agile?",Journal of Operations Management, Vol.33-34, pp. 71-82.

Guide, V.D.R. and Ketokivi, M. (2015), "Notes from the Editors: Redefining some methodological criteria for the journal", Journal of Operations Management, Vol.37, pp. v-viii.

Gunasekaran, A., Patel, C. and Tirtiroglu, E. (2001), "Performance measures and metrics in a supply chain environment", International Journal of Operations \& Production Management, Vol. 21 No. 1-2, pp. 71-87.

Gupta, A.K. and Govindarajan, V. (2000), "Knowledge flows within multinational corporations", Strategic Management Journal, Vol.21 No.4, pp.473-496.

Hair, J., Black, W., Babin, J., and Anderson, R. (2010), Multivariate Data Analysis. A global perspective, Prentice Hall, Upper Saddle River NJ.

Hayes, A.F. (2013), Introduction to Mediation, Moderation, and Conditional Process Analysis. A regression-based approach, The Guilford Press, New York . 
He, P., Xu, X. and Hua, Z. (2012), “A New Method for Guiding Process Flexibility Investment: Flexibility Fit Index”, International Journal of Production Research, Vol. 50 No.14, pp. 3718 3737.

Henseler, J., Ringle, C.M., and Sarstedt, M. (2015), "A new criterion for assessing discriminant validity in variance-based structural equation modeling", Journal of the Academy of Marketing Science, Vol. 43 No 1, pp. 115-135.

Huber, G.P.(1996), "Organizational learning: a guide for executives in technology-critical organizations", International Journal of Technology Management, Vol.11 No.6-7, pp.821-832.

Hult. G.T.M., Ketchen Jr., D.J. and Nichols Jr., E.L.N. (2003), "Organizational learning as a strategic resource in supply management", Journal of Operations Management, Vol.21 No.5, pp.541-556.

Karim, S. (2006), "Modularity in organizational structure: the reconfiguration of internally developed and acquired business units", Strategic Management Journal, Vol.27 No.9, pp.799823.

Katila, R. and Ahuja, G. (2002), "Something old, something new: a longitudinal study of search behavior and new product introduction", Academy of Management Journal, Vol.45No.6, pp.1183-1194.

Keats, B.W. and Hitt, M.A. (1988), "A causal model of linkages among environmental dimensions, macro organizational characteristics and performance", Academy of Management Journal, Vol.31 No.3, pp.570-590.

Ketchen, D.J. and Guinipero, L.C. (2004), "The intersection of strategic management and supply chain management", Industrial Marketing Management, Vol.33 No.1, pp.51-56.

Kim, M., Suresh, N.C. and Kocabasoglu-Hillmer, C. (2013), “An impact of manufacturing flexibility and technological dimensions of manufacturing strategy on improving supply chain responsiveness: Business environment perspective", International Journal of Production Research, Vol. 51 No.18, pp.5597-5611.

Kogut, B. and Zander, U. (1992), "Knowledge of the firm, combinative capabilities, and the replication of technology", Organization Science, Vol.3 No.3, pp.383-397.

Kovach, J.J., Hora, M., Manikas, A. and Patel, P.C. (2015), "Firm performance in dynamic environments: the role of operational slack and operational scope", Journal of Operations Management, Vol. 37, pp. 1-12.

Krajewski, L., Wei, J.C. and Tang, L-L. (2005), "Responding to schedule changes in build-to-order supply chains", Journal of Operations Management, Vol. 23 No.5, pp. 452-469.

Kristal, M.M., Huang, X. and Roth, A.V. (2010), "The Effect of an Ambidextrous Supply Chain Strategy on Combinative Competitive Capabilities and Business Performance", Journal of Operations Management, Vol. 28 No. 5, pp. 415-429. 
Lee, P.-Y., Chen, H.-H. and Shyr, Y.-H. (2011), "Driving dynamic knowledge articulation and dynamic capabilities development of service alliance firms", Service Industries Journal, Vol.31No.3, pp. 2223-2242.

Liang, H., Saraf, N., Hu, Q. and Xue, Y. (2007), "Assimilation of Enterprise systems: the effect of institutional pressures and the mediating role of top management" MIS Quarterly, Vol. 31 No.1, pp. 59-87.

Little, R.J.A. (1988), "Missing-Data Adjustments in Large Surveys", Journal of Business \& Economic Statistics, Vol. 6 No. 3, pp. 287-296.

Llorens, F.J., Molina, L.M. and Verdu, A.J. (2005), "Flexibility of manufacturing systems, strategic change and performance", International Journal of Production Economics, Vol.98No.3, pp.273283.

Loufrani-Fedida, N. and Saglietto, L. (2016), "Mechanisms for managing competencies in projectbased organizations: an integrative multilevel analysis", Long Range Planning, Vol.49, pp. 72 89.

Lummus, R.R., Vokurka, R.J. and Duclos, L.K. (2005), "Delphi study on Supply Chain Flexibility”, International Journal of Production Research, Vol. 43 No.13, pp. 2687-2708.

Malhotra, A., Gosain,S. and Sawy O.A.E. (2005), "Absorptive capacity configurations in supply chains: gearing for partner-enabled market knowledge creation", MIS Quarterly, Vol.29 No.1, pp.145-187.

Manuj, I., Omar, A. and Pohlen, T.L. (2014), "Inter-Organizational Learning in Supply Chains: A focus on logistics service providers and their customers", Journal of Business Logistics, Vol.35 No.2, pp.103-120.

Martínez-Sánchez, A. and Pérez-Pérez, M. (2005), "Supply chain flexibility and firm performance", International Journal of Operations \& Production Management, Vol.25 No.7, pp.681-700.

Miller, C.C., Ogilvie, D.T.,and Glick, W.H. (2006), "Assessing the external environment: an enrichment of the archival tradition" in Ketchen, D.J., Bergh, D.D. (ed.) Research Methodology in Strategy and Management, Volume 3 Emerald Group Publishing Limited, pp.97 - 122.

Mitchell, J.R., Shepherd, D. and Sharfman, M. (2011), "Erratic strategic decisions: managers are inconsistent in strategic decision making", Strategic Management Journal, Vol.32 No.7, pp.683704.

Moon, K.K.L., Yi,C.C. and Ngai, E.W.T. (2012), "An Instrument for Measuring Supply Chain Flexibility for the Textile and Clothing Companies", European Journal of Operational Research, Vol. 222 No. 2, pp. 191-203.

Moore, G.C. and Benbasat, I. (1991), "Development of an instrument to measure the perceptions of adopting an information technology innovation", Information Systems Research, Vol.2 No.3, pp. 192-222.

Nunnally, J. (1978), Psychometric Theory, Second ed., McGraw-Hill, New York, NY. 
Nonaka, I. (1994), “A dynamic theory of organizational knowledge creation”, Organization Science, Vol.5No.1, pp.14-37

O'Connor, G.C. (2008), "Major innovation as a dynamic capability: a systems approach”, Journal of Product Innovation Management, Vol.25 No.4, pp.313-330.

O'Reilly, C.A. and Tushman, M.L. (2008), "Ambidexterity as a dynamic capability: resolving the innovator's dilemma". In: Brief, A.P. and Staw, B.M. (Eds.), Research in Organizational Behavior, vol. 28, Oxford, Elsevier, pp. 185-206.

Pagell, M. and Krause, D.R. (1999), "A multiple-method study of environmental uncertainty and manufacturing flexibility", Journal of Operations Management, Vol. 17 No.3, pp. 307-325.

Patel, P.C., Terjesen, S. and Li, D. (2012), "Enhancing Effects of Manufacturing Flexibility through Operational Absorptive Capacity and Operational Ambidexterity", Journal of Operations Management, Vol. 30 No. 3, pp. 201-220.

Podsakoff, P.M., MacKenzie, S.B., Lee, J. and Podsakoff, N.P. (2003), "Common method biases in behavioral research: a critical review of the literature and recommended remedies", Journal of Applied Psychology, Vol.88 No.5, pp. 879-903.

Podsakoff, P.M.; Organ, D.W. (1986), "Self-reports in organizational research: problems and prospects", Journal of Management, Vol. 12 No.4, pp. 531-544.

Preacher, K. J. and Hayes, A. F. (2008), "Asymptotic and resampling strategies for assessing and comparing indirect effects in multiple mediator models" Behavior Research Methods, Vol. 40 No.3, pp. 879-891

Riedl, D.F., Kaufmann, L., an Gaeckler, J. (2014), "Statistical power of structural equation models in SCM research", Journal of Purchasing and Supply Management, Vol. 20 No. 3 pp. 208-212.

Rojo, A., Llorens-Montes, J. and Perez-Arostegui, M.N. (2016), "The impact of ambidexterity on supply chain flexibility fit", Supply Chain Management: an International Journal, Vol.21 No.4, pp.433-452.

Rosenzweig, E.D. (2009), "A contingent view of e-collaboration and performance in manufacturing", Journal of Operations Management, Vol.27 No.6, pp.462-478.

Ruiz-Moreno, A., Molina-Fernandez, L.M. and Llorens-Montes, F.J. (2009), “The moderating effect of slack resources on the relationship between quality management and organisational learning", International Journal of Production Research, Vol.47 No.19, pp. 5501-5523.

Sanchez, R. (1995), "Strategic flexibility in Product Competition", Strategic Management Journal, Vol.16 No.1, pp.135-159.

Schumacker, R.E. and Lomax, R.G. (1996), A Beginner's Guide to Structural Equation Effects in Structural Equation Modeling, Lawrence Erlbaum, Mahwah, NJ.

Sebastiao, H.J. and Golicic, S.(2008), "Supply chain strategy for nascent firms in emerging technology markets", Journal of Business Logistics, Vol.29No.1, pp.75-91.

Slack, N. (1983), "Flexibility as a manufacturing objective", International Journal of Operations \& Production Management, Vol. 3 No. 3, pp. 4-13. 
Slack, N. (1987), “The flexibility of manufacturing systems", International Journal of Operations \& Production Management, Vol. 7 No. 4, pp. 35-45.

Song, M. and Di Benedetto, C.A. (2008), "Supplier's involvement and success of radical new product development in new ventures", Journal of Operations Management, Vol.26No.1, pp.122.

Stevenson, M. and Spring, M. (2007), "Flexibility from a Supply Chain Perspective: Definition and Review", International Journal of Operations \& Production Management, Vol. 27 No.7, pp. $685-713$.

Stevenson, M. and Spring, M. (2009), "Supply Chain Flexibility: An Inter-firm Empirical Study", International Journal of Operations \& Production Management, Vol. 29 No.9, pp. 946-971.

Swafford,P., Ghosh,S. and Murthy, N. (2006), "The antecedents of supply chain agility of a firm: scale development and model testing”, Journal of Operations Management, Vol.24 No.2, pp.170188.

Swink, M., Narasimhan, R. and Kim, S.W. (2005), "Manufacturing practices and strategy integration: Effects on cost efficiency, flexibility, and market-based performance", Decision Sciences, Vol.36 No.3, pp.427-457.

Teece, D.J. (2007), "Explicating dynamic capabilities: the nature and microfoundations of (sustainable) enterprise performance", Strategic Management Journal, Vol.28 No.13, pp.13191350.

Teece, D.J., Pisano, G. and Shuen, A.A. (1997), "Dynamic capabilities and strategic management", Strategic Management Journal, Vol.18 No.7, pp.509-533.

Toon, M.A., Morgan, R.E., Lindgreen, A., Vanhamme, J. and Hingley, M.K. (2016), "Processes and integration in the interaction of purchasing and marketing: considering synergy and symbiosis", Industrial Marketing Management, Vol.52, pp.74-81.

Trkman, P., Budler, M. and Groznik, A. (2015), "A business model approach to supply chain management”, Supply Chain Management: an International Journal, Vol.20 No.6, pp. 587-602.

Tu, Q., Vonderembse, M.A., Ragu-Nathan, T.S. and Sharkey, T.W.(2006), “Absorptive capacity: enhancing the assimilation of time-based manufacturing practices", Journal of Operations Management, Vol. 24 No.5, pp.692-710.

Upton, D. (1995), “What really makes factories flexible?”, Harvard Business Review, Vol. 73 No.4, pp. 74-84.

Vanpoucke,E., Vereecke, A. and Wetzels, M. (2014), "Developing supplier integration capabilities for sustainable competitive advantage: a dynamic capabilities approach", Journal of Operations Management, Vol.32 No.7-8, pp.446-461.

Venkatraman, N. (1989), “The concept of fit in strategy research: toward verbal and statistical correspondence", Academy of Management Review, Vol.14 No.3, pp. 423-444. 
Voorhees, C.M., Brady, M.K., Calantone, R. and Ramirez, E. (2016), "Discriminant validity testing in marketing: an analysis, causes for concern, and proposed remedies", Journal of the Academy of Marketing Science, Vol.44 No.1, pp.119-134.

Wang, L., Yeung, J.H.Y. and Zhang, M. (2011), "The impact of trust and contract on innovation performance: the moderating role of environmental uncertainty", International Journal of Production Economics, Vol. 134 No.1, pp.114-122.

Ward, P.T. and Duray, R. (2000), "Manufacturing strategy in context: environment, competitive strategy, and manufacturing strategy", Journal of Operations Management, Vol. 18 No.1, pp. $123-128$.

Whetten, D.A., Felin, T. and King, B.G. (2009), "The practice of theory borrowing in organizational studies: current issues and future directions", Journal of Management, Vol.35 No.3, pp.537-563.

Williams, L.J., Edwards, J.R. and Vandenberg, R.J. (2003), "Recent advances in causal modeling methods for organizational and management research", Journal of Management, Vol. 29 No.6, pp.903-936.

Wilhelm, H., Schloemer, M. and Maurer, I. (2015), "How dynamic capabilities affect the effectiveness and efficiency of operating routines under high and low levels of environmental dynamism", British Journal of Management, Vol.26 No.2, pp.327-345.

Winter, S.G. (2003), “Understanding dynamic capabilities", Strategic Management Journal, Vol. 24 No.10, pp. 991-995.

Yi, C.Y., Ngai, E.W.T. and Moon, K-L (2011), "Supply chain flexibility in an uncertain environment: exploratory findings from five case studies", Supply Chain Management: an International Journal, Vol.16 No.4, pp.271-283.

Yu, K., Cadeaux, J. and Luo, B.N. (2015), "Operational flexibility: Review and meta-analysis", International Journal of Production Economics, Vol.169 No.November, pp.190-202.

Zablith, F., Faraj, S. and Azad, B. (2016), "Organizational knowledge generation: lessons from online communities”, Business Process Management Journal, Vol. 22 No.1, pp.33-55.

Zahra, S.A. and George, G. (2002), "Absorptive capacity: a review, reconceptualization, and extension", Academy of Management Review, Vol.27 No.2, pp.185-203.

Zahra, S.A., Sapienza, H.J. and Davidsson, P. (2006), "Entrepreneurship and dynamic capabilities: a review, model and research agenda”, Journal of Management Studies, Vol. 43 No.4, pp.917-955.

Zander, U. and Kogut, B. (1995), "Knowledge and the speed of the transfer and imitation of organizational capabilities: an empirical test", Organization Science, Vol.6No.1, pp.76-92.

Zappa, P. and Robins, G. (2016), "Organizational learning across multi-level networks", Social Networks, Vol.44, pp.295-306.

Zhao, Z.J. and Anand, J. (2009), “A multilevel perspective on knowledge transfer: Evidence from the Chinese automotive industry", Strategic Management Journal, Vol.30, pp.959-983.

Zhao, X., Lynch, J. G. and Chen, Q. (2010), "Reconsidering Baron and Kenny: myths and truths about mediation analysis" Journal of Consumer Research, Vol. 37No. 2, pp. 197-206. 
Zollo, M. and Singh, H. (2004), "Deliberate learning in corporate acquisitions: post-acquistion strategies and integration capability in US bank mergers", Strategic Management Journal, Vol.25No.13, pp.1233-1256.

Zollo, M. and Winter, S.G. (2002), "Deliberate learning and the evolution of dynamic capabilities", Organization Science, Vol.13 No.3, pp.339-351. 


\section{Appendix A: Items used in This Study}

Environmental Dynamism (Ward and Duray, 2000)

ED1. The rate at which products and services become outdated.

ED2. The rate of innovation of new products and services.

ED3. The rate of change of tastes and preferences of customers in your industry.

Organisational Learning (García-Morales et al., 2007)

OL1. The organisation has acquired and used much new and relevant knowledge that provided competitive advantage over the last three years.

OL2. The organisation's members have acquired some important capacities and skills that provided competitive advantage over the last three years.

OL3. Organisational improvements have been influenced fundamentally by new knowledge entering the organisation over the last three years.

OL4. The organisation is an organisation that fosters learning.

Operational Absorptive Capacity (Patel et al.,2012)

Acquisition, Operations and SC Department

Acq1. Has frequent interactions with other departments in the firm to acquire new knowledge related to product development, process innovation, or logistics and distribution practices.

Acq2. Employees are engaged in cross-functional work.

Acq3. Collects operations related information (product, process, or logistics and distribution practices) through informal means (e.g. lunch or social gatherings with customers and suppliers, trade partners and other stakeholders).

Acq4. Is hardly in touch with other departments in the firm.

Acq5. Organises special meetings with customers, suppliers, or third parties to acquire new knowledge on process, product, logistics and distribution related innovation.

Acq6. Employees in operations and SC regularly approach third parties such as supply chain institutes, and suppliers to gather information. 
Assimilation, Operations and SC Department

As1. Is slow to recognise shifts in the operational environment (e.g. competition, process innovation, logistics and distribution)

As2. Is able to quickly identify operations related (product, process, or logistics and distribution) innovations to serve our clients.

As3. Analyses and interpret changing market and operational demand.

\section{$\underline{\text { Transformation, Operations and SC Department }}$}

Tra1. Regularly considers the consequences of changing market/operational demands in terms of new products, processes, and logistics and distribution.

Tra2. Employees record and store newly acquired knowledge for future reference.

Tra3. Quickly recognises the usefulness of new external operational and SC knowledge to existing operational and SC knowledge.

Tra.4. Employees hardly share practical experiences with each other.

Tra5. Laboriously grasps the opportunities from new external knowledge.

Tra6. Periodically meets to discuss consequences of new product, process or logistics and distribution developments.

\section{Exploitation, Operations and SC Department}

Ex1. Clearly knows how activities within our unit should be performed.

Ex2. Is less responsive to customer complaints.

Ex3. Has a clear division of roles and responsibilities

Ex4. Constantly considers how to better exploit operational and SC knowledge.

Ex5. Has difficulty implementing new products and new processes.

Ex6. Employees have a common language regarding our products, processes, and logistics and distribution.

Supply Chain Flexibility (Moon et al., 2012)

\section{Sourcing Flexibility}

SF1. Number of available suppliers

SF2. Range of products and services provided by major suppliers

SF3. Range of suppliers that provide major materials/components/products 
Operating System Flexibility

OSF1. Range of new products or services the firm can develop every year.

OSF2. Ability to change output volume

OSF3. Ability to change products and services mix

OSF4. Ability to adjust manufacturing facilities and processes

\section{Distribution Flexibility}

DF1. Ability to change storage space, loading capability, and other distribution installations

DF2. Ability to change delivery modes

DF3. Ability to transfer delivery schedules

Information System Flexibility

ISF1. Support of information systems in transportation and distribution management

ISF2. Support of information systems in firm inventory management

\section{Appendix B: Tests of Robustness}

[Take in Figure 3]

[Take in Figure 4] 
Figure 1: Theoretical Framework of the Study

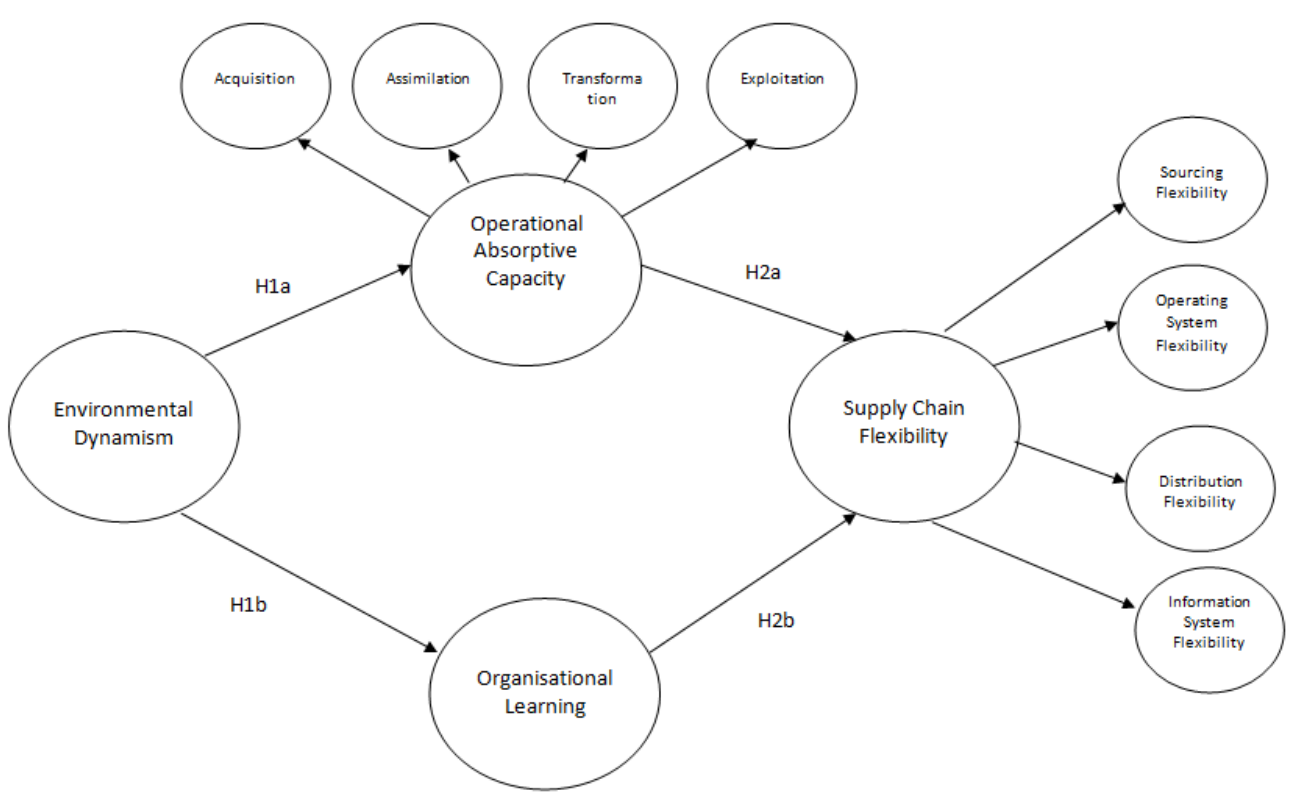

Figure 2: Structural Equation Modeling Results with Standardised Parameter Estimated

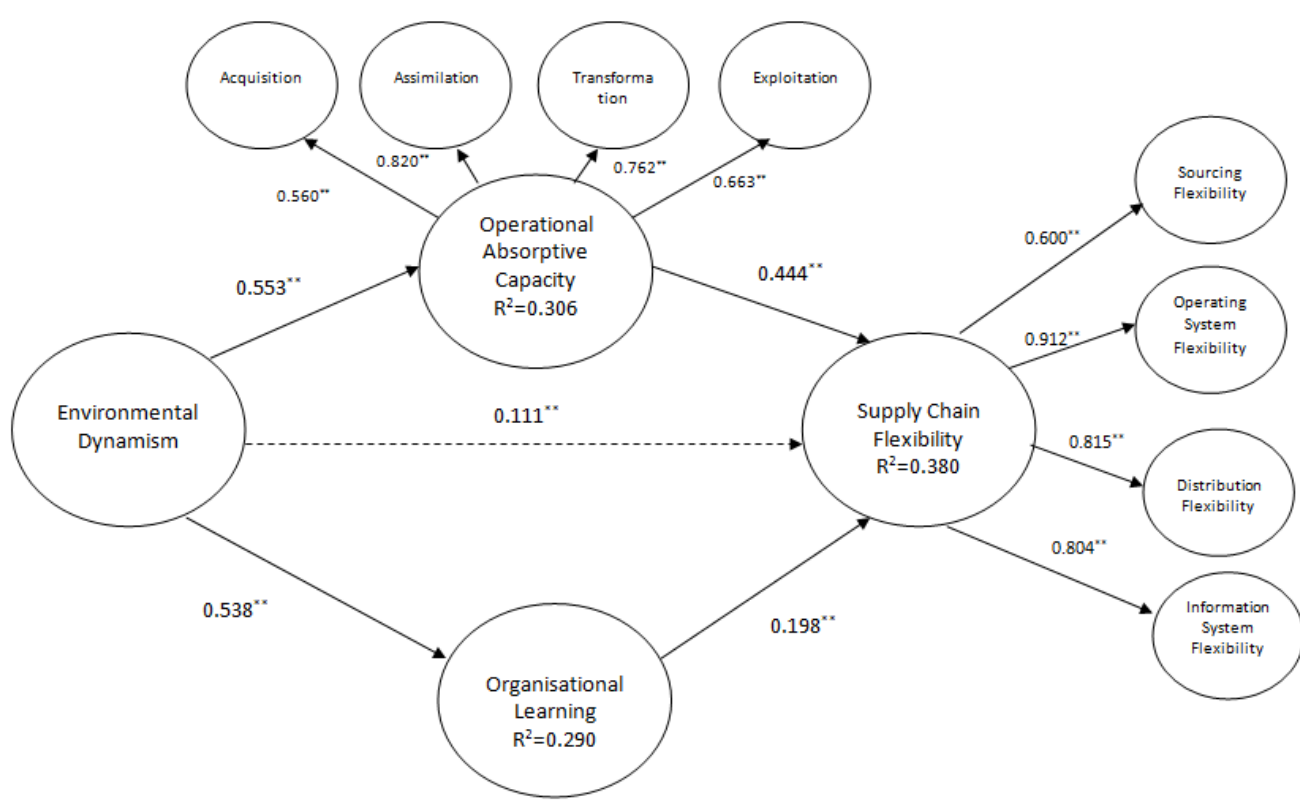

Hypothesised relationship

Non-hypothesised 
Figure 3: Alternative Model 1

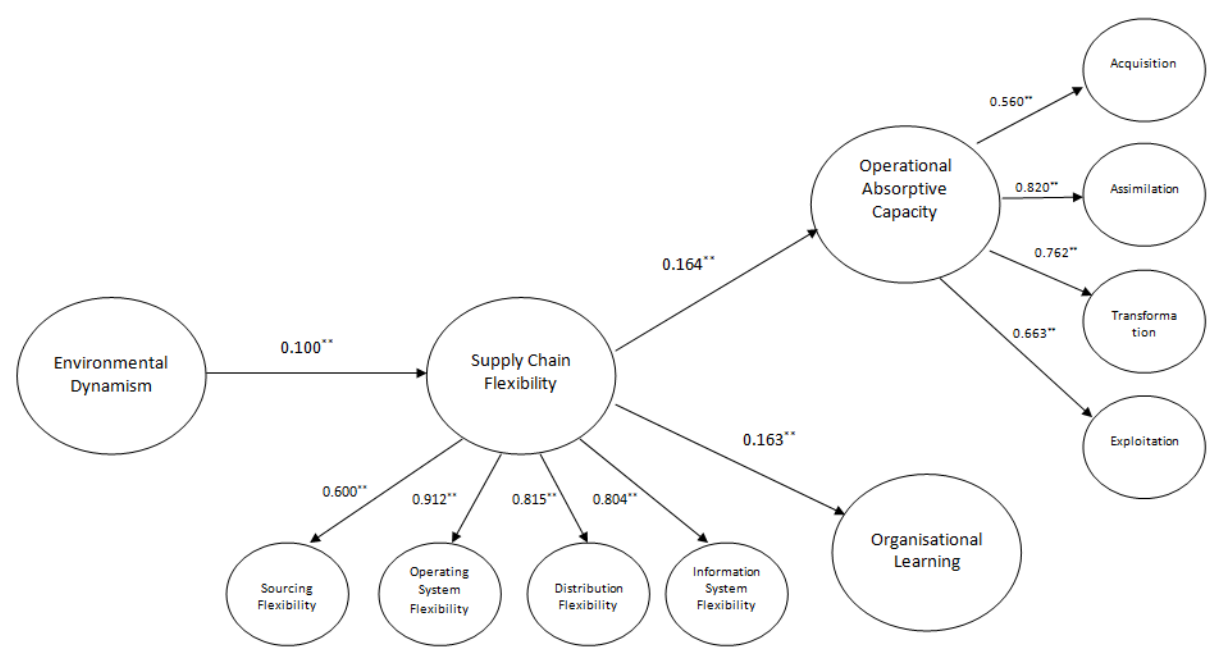

Figure 4: Alternative Model 2

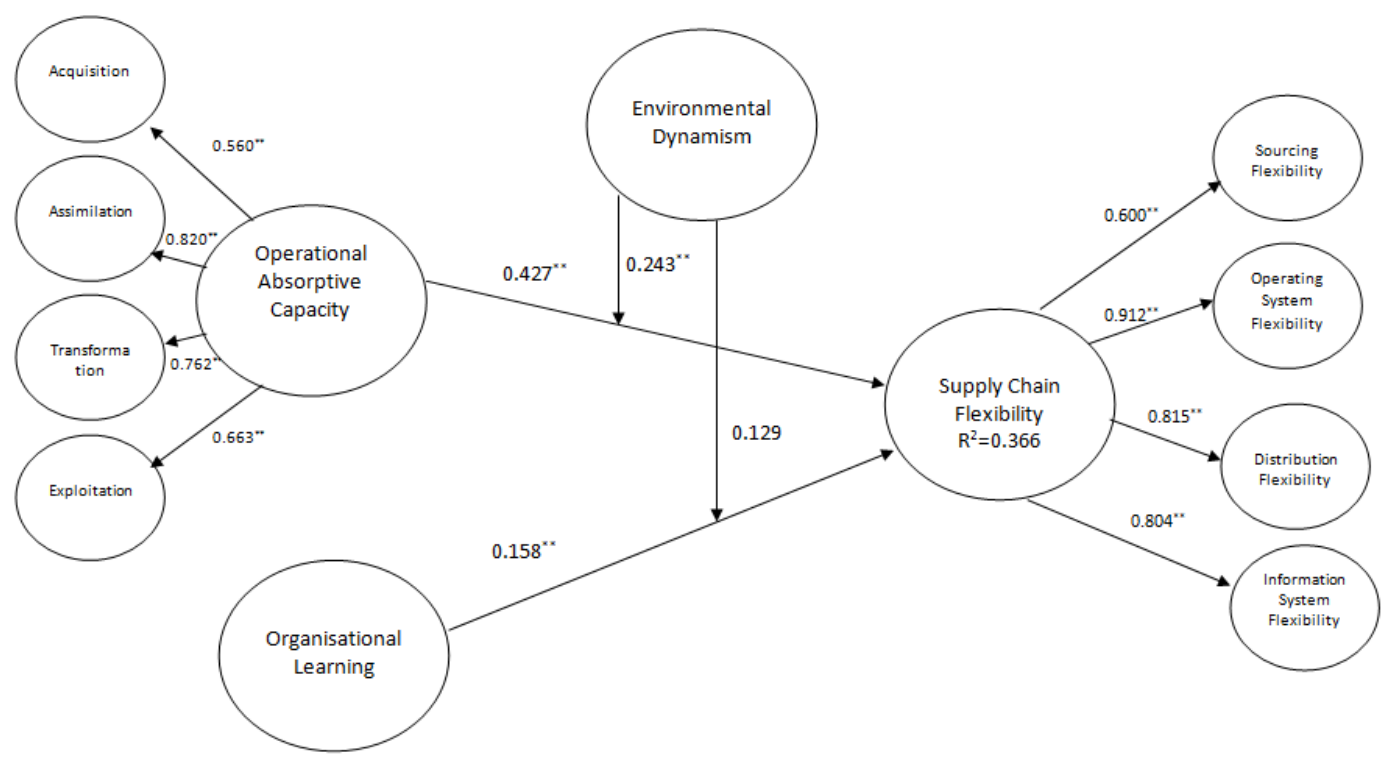


Table I: Sample Characteristics

\begin{tabular}{|c|c|c|}
\hline & $\mathbf{N}$ & Percentage $(\%)$ \\
\hline \multicolumn{3}{|l|}{ Manufacturing Industry ${ }^{1}$} \\
\hline Food products, beverages, and tobacco & 3 & 1 \\
\hline Textiles and apparel & 5 & 1.65 \\
\hline Chemistry and pharmaceuticals & 26 & 8.61 \\
\hline Plastics & 28 & 9.27 \\
\hline Computers, electronics, and optical equipment & 23 & 7.61 \\
\hline Electrical equipment & 30 & 9.93 \\
\hline Machinery and equipment & 110 & 36.42 \\
\hline Furniture & 47 & 15.57 \\
\hline Automotive & 25 & 8.29 \\
\hline Other & 5 & 1.65 \\
\hline Total & 302 & 100 \\
\hline \multicolumn{3}{|l|}{ Respondent's Job Title } \\
\hline Supply Chain Manager & 81 & 26.82 \\
\hline Purchasing manager & 130 & 43.05 \\
\hline Top Level Manager & 91 & 30.13 \\
\hline Total & 302 & 100 \\
\hline \multicolumn{3}{|l|}{ Size of Firm (No. Employees) } \\
\hline $10-49$ & 69 & 22.85 \\
\hline $50-250$ & 142 & 47.02 \\
\hline $251-1000$ & 58 & 19.20 \\
\hline Over 1000 & 33 & 10.93 \\
\hline Total & 302 & 100 \\
\hline \multicolumn{3}{|l|}{ Annual Sales of Company } \\
\hline Less than $€ 1$ million & 50 & 16.56 \\
\hline$€ 1-7$ million & 94 & 31.12 \\
\hline More than $€ 7$ million and less $€ 40$ million & 100 & 33.11 \\
\hline More than $€ 40$ million & 58 & 19.21 \\
\hline (2) & 302 & 100 \\
\hline
\end{tabular}


Table II: CFA of Measurement Scales of First-Order Constructs

\begin{tabular}{|c|c|c|c|c|}
\hline Items & Factor Loadings & t-value & $\mathbf{R 2}$ & Scale Reliability \\
\hline \multicolumn{5}{|c|}{ Organisational Learning (OL) } \\
\hline OL1 & 0.885 & $\mathrm{a}$ & 0.783 & \multirow{4}{*}{$\begin{array}{l}\text { CR: } 0.951 \\
\text { AVE: } 0.829 \\
\alpha: 0.940\end{array}$} \\
\hline OL2 & 0.920 & 24.656 & 0.847 & \\
\hline OL3 & 0.945 & 26.230 & 0.893 & \\
\hline OL4 & 0.892 & 22.923 & 0.796 & \\
\hline \multicolumn{5}{|c|}{$\begin{array}{l}\text { E Environmental Dynamism } \\
\text { (ED) }\end{array}$} \\
\hline ED1 & 0.951 & $\mathrm{a}$ & 0.904 & \multirow{3}{*}{$\begin{array}{l}\text { CR: } 0.972 \\
\text { AVE: } 0.920 \\
\alpha: 0.962\end{array}$} \\
\hline ED2 & 0.980 & 42.679 & 0.960 & \\
\hline ED3 & 0.946 & 35.969 & 0.895 & \\
\hline \multicolumn{5}{|l|}{ Acquisition (Acq) } \\
\hline Acq1 & 0.931 & $\mathrm{a}$ & 0.867 & \multirow{6}{*}{$\begin{array}{l}\text { CR: } 0.970 \\
\text { AVE: } 0.889 \\
\alpha: 0.969\end{array}$} \\
\hline Acq2 & Dropped & & & \\
\hline Acq3 & 0.949 & 33.417 & 0.901 & \\
\hline Acq4 & 0.985 & 39.308 & 0.971 & \\
\hline Acq5 & Dropped & & & \\
\hline Acq6 & 0.905 & 28.064 & 0.819 & \\
\hline \multicolumn{5}{|l|}{ Assimilation (As) } \\
\hline As1 & 0.781 & $\mathrm{a}$ & 0.611 & \multirow{3}{*}{$\begin{array}{l}\text { CR: } 0.750 \\
\text { AVE: } 0.501 \\
\alpha: 0.813\end{array}$} \\
\hline As2 & 0.860 & 14.113 & 0.740 & \\
\hline As3 & 0.809 & 13.819 & 0.654 & \\
\hline \multicolumn{5}{|l|}{ Transformation (Tra) } \\
\hline Tra1 & 0.935 & $\mathrm{a}$ & 0.875 & \multirow{6}{*}{$\begin{array}{l}\text { CR: } 0.976 \\
\text { AVE: } 0.870 \\
\alpha: 0.971\end{array}$} \\
\hline Tra2 & 0.925 & 30.708 & 0.855 & \\
\hline Tra3 & 0.979 & 39.564 & 0.958 & \\
\hline Tra4 & 0.874 & 25.558 & 0.764 & \\
\hline Tra5 & 0.968 & 37.331 & 0.937 & \\
\hline Tra6 & 0.912 & 29.245 & 0.832 & \\
\hline \multicolumn{5}{|l|}{ Exploitation (Exp) } \\
\hline Ex1 & 0.855 & $\mathrm{a}$ & 0.732 & \multirow{5}{*}{$\begin{array}{l}\text { CR: } 0.941 \\
\text { AVE: } 0.762 \\
\alpha: 0.908\end{array}$} \\
\hline Ex2 & 0.920 & 22.353 & 0.847 & \\
\hline Ex3 & 0.807 & 17.629 & 0.652 & \\
\hline Ex4 & 0.904 & 21.598 & 0.817 & \\
\hline Ex5 & 0.873 & 20.241 & 0.763 & \\
\hline Ex6 & Dropped & & & \\
\hline \multicolumn{5}{|c|}{ Sourcing Flexibility (SF) } \\
\hline SF1 & 0.821 & $\mathrm{a}$ & 0.674 & \multirow{3}{*}{$\begin{array}{l}\text { CR: } 0.884 \\
\text { AVE: } 0.717 \\
\alpha: 0.816\end{array}$} \\
\hline SF2 & 0.834 & 15.993 & 0.696 & \\
\hline SF3 & 0.884 & 16.584 & 0.782 & \\
\hline \multicolumn{5}{|c|}{ Operating System Flexibility (OSF) } \\
\hline OSF1 & 0.925 & $\mathrm{a}$ & 0.855 & \multirow{4}{*}{$\begin{array}{l}\text { CR: } 0.967 \\
\text { AVE: } 0.878 \\
\alpha: 0.950\end{array}$} \\
\hline OSF2 & 0.943 & 31.257 & 0.890 & \\
\hline OSF3 & 0.970 & 34.678 & 0.940 & \\
\hline OSF4 & 0.909 & 27.605 & 0.827 & \\
\hline \multicolumn{5}{|c|}{ Distribution Flexibility (DF) } \\
\hline DF1 & 0.825 & $\mathrm{a}$ & 0.680 & \multirow{3}{*}{$\begin{array}{l}\text { CR: } 0.931 \\
\text { AVE: } 0.818 \\
\alpha: 0.863 \\
\end{array}$} \\
\hline DF2 & 0.953 & 21.384 & 0.909 & \\
\hline DF3 & 0.931 & 20.945 & 0.867 & \\
\hline \multicolumn{5}{|c|}{ Information System Flexibility (ISF) } \\
\hline ISF1 & 0.911 & $\mathrm{a}$ & 0.830 & \multirow{2}{*}{$\begin{array}{l}\text { CR: } 0.714 \\
\text { AVE: } 0.556 \\
\alpha: 0.871\end{array}$} \\
\hline ISF2 & 0.915 & 11.083 & 0.831 & \\
\hline
\end{tabular}


Table III: CFA of Measurement Scales of Second-Order Constructs

\begin{tabular}{|c|c|c|c|c|}
\hline Factor & $\begin{array}{c}\text { Standardised } \\
\text { Parameters }\end{array}$ & t-value & $\mathbf{R}^{2}$ & $\begin{array}{c}\text { Scale } \\
\text { Reliability }\end{array}$ \\
\hline \multicolumn{5}{|c|}{ Operational Absorptive Capacity } \\
\hline Acquisition & 0.560 & $\mathrm{a}^{2}$ & 0.516 & \multirow{4}{*}{$\begin{array}{l}\text { CR: } 0.798 \\
\text { AVE: } 0.501 \\
\alpha: 0.926\end{array}$} \\
\hline Assimilation & 0.820 & 34.479 & 0.673 & \\
\hline Transformation & 0.762 & 9.765 & 0.580 & \\
\hline Exploitation & 0.663 & 21.170 & 0.544 & \\
\hline \multicolumn{5}{|c|}{ CFI 0.983.; NFI 0.961; IFI 0.983; GFI 0.923; AGFI 0.901; RMSEA 0.048} \\
\hline \multicolumn{5}{|l|}{ Supply Chain Flexibility } \\
\hline Sourcing Flexibility & 0.600 & $\mathrm{a}$ & 0.505 & \multirow{4}{*}{$\begin{array}{r}\text { CR: } 0.867 \\
\text { AVE: } 0.625 \\
\alpha: 0.869\end{array}$} \\
\hline Operating System Flexibility & 0.912 & 17.664 & 0.840 & \\
\hline Distribution Flexibility & 0.815 & 17.125 & 0.749 & \\
\hline Information System Flexibility & 0.804 & 16.898 & 0.829 & \\
\hline
\end{tabular}

${ }^{2}$ a indicates that the parameter was set to 1.0. However, setting a parameter different from 1.0 also produced statistically significant scale indicators.

Table IV: Correlation Matrix

\begin{tabular}{|c|c|c|c|c|c|c|c|c|c|c|}
\hline & OL & ED & Acq & As & Tra & $\mathbf{E x}$ & SF & OSF & $\overline{D F}$ & ISF \\
\hline OL & 0.910 & & & & & & & & & \\
\hline ED & $0.590^{* * * * x^{2}}$ & 0.959 & & & & & & & & \\
\hline Acq & $0.400^{* * * *}$ & $0.755^{* * *}$ & 0.943 & & & & & & & \\
\hline As & $0.482^{* * * *}$ & $0.610^{* * * *}$ & $0.604^{* * *}$ & 0.708 & & & & & & \\
\hline Tra & $0.556^{* * *}$ & $0.739^{* * *}$ & $0.734^{* * *}$ & $0.573^{* * *}$ & 0.934 & & & & & \\
\hline $\mathbf{E x}$ & $0.472^{* * * *}$ & $0.657^{* * * *}$ & $0.650^{* * * *}$ & $0.527^{* * *}$ & $0.631^{* * *}$ & 0.873 & & & & \\
\hline SF & $0.580^{* * * *}$ & $0.453^{* * * *}$ & $0.718^{* * *}$ & $0.600^{* * *}$ & $0.730^{* * *}$ & $0.649^{* * *}$ & 0.847 & & & \\
\hline OSF & $0.444^{* * * *}$ & $0.522^{* * * *}$ & $0.556^{* * *}$ & $0.465^{* * *}$ & $0.550^{* * *}$ & $0.493^{* * *}$ & $0.550^{* * *}$ & 0.937 & & \\
\hline DF & $0.604^{* * * *}$ & $0.492^{* * *}$ & $0.771^{* * *}$ & $0.630^{* * *}$ & $0.722^{* * * *}$ & $0.671^{* * * *}$ & $0.650^{* * *}$ & $0.580^{* * *}$ & 0.904 & \\
\hline ISF & $0.540^{* * * * *}$ & $0.613^{* * * *}$ & $0.753^{* * * *}$ & $0.621^{* * *}$ & $0.708^{* * *}$ & $0.660^{* * *}$ & $0.725^{* * *}$ & $0.575^{* * *}$ & $0.742^{* * * *}$ & 0.746 \\
\hline
\end{tabular}

Table V: HTMT Ratio

\begin{tabular}{|c|c|c|c|c|c|c|c|c|c|c|}
\hline & OL & ED & Acq & As & Tra & Ex & SF & OSF & DF & ISF \\
\hline OL & & & & & & & & & & \\
\hline ED & 0.845 & & & & & & & & & \\
\hline Acq & 0.575 & 0.846 & & & & & & & & \\
\hline As & 0.847 & 0.836 & 0.830 & & & & & & & \\
\hline Tra & 0.818 & 0.847 & 0.845 & 0.806 & & & & & & \\
\hline Ex & 0.782 & 0.849 & 0.843 & 0.835 & 0.837 & & & & & \\
\hline SF & 0.840 & 0.511 & 0.813 & 0.831 & 0.846 & 0.847 & & & & \\
\hline OSF & 0.848 & 0.777 & 0.831 & 0.849 & 0.841 & 0.849 & 0.827 & & & \\
\hline DF & 0.848 & 0.538 & 0.847 & 0.846 & 0.811 & 0.849 & 0.719 & 0.846 & & \\
\hline ISF & 0.762 & 0.675 & 0.832 & 0.839 & 0.800 & 0.841 & 0.806 & 0.844 & 0.800 & \\
\hline
\end{tabular}


Table VI: Common Method Bias Analysis

\begin{tabular}{|c|c|c|c|c|}
\hline Item & $\begin{array}{c}\text { Substantive } \\
\text { Factor Loading }\end{array}$ & $\mathbf{R 1}^{2}$ & $\begin{array}{l}\text { Method Factor } \\
\text { Loading }\end{array}$ & $\mathbf{R} 2^{2}$ \\
\hline OL1 & $0.710^{* * *}$ & 0.504 & $0.263^{* *}$ & 0.069 \\
\hline OL2 & $0.715^{* *}$ & 0.511 & $0.199^{* *}$ & 0.040 \\
\hline OL3 & $0.799^{* * *}$ & 0.638 & 0.102 & 0.010 \\
\hline OL4 & $0.720^{* *}$ & 0.518 & $0.150^{* *}$ & 0.022 \\
\hline ED1 & $0.964^{* *}$ & 0.929 & 0.002 & 0.000 \\
\hline ED2 & $0.908^{* *}$ & 0.824 & 0.048 & 0.002 \\
\hline ED3 & $0.821^{* *}$ & 0.674 & 0.091 & 0.008 \\
\hline Acq1 & $0.730^{* * *}$ & 0.533 & $0.179^{* * *}$ & 0.032 \\
\hline Acq2 & \multicolumn{4}{|l|}{ Dropped } \\
\hline Acq3 & $0.757^{* * *}$ & 0.573 & $0.170^{* *}$ & 0.029 \\
\hline$\frac{1}{A c q} 4$ & $0.810^{* * *}$ & 0.656 & $0.150^{* *}$ & 0.022 \\
\hline Acq5 & \multicolumn{4}{|l|}{ Dropped } \\
\hline Acq6 & $0.824^{* *}$ & 0.679 & 0.103 & 0.011 \\
\hline As1 & $0.711^{* *}$ & 0.505 & $0.194^{* *}$ & 0.038 \\
\hline As2 & $0.800^{* *}$ & 0.640 & 0.104 & 0.011 \\
\hline As3 & $0.825^{* *}$ & 0.681 & 0.100 & 0.010 \\
\hline Tra1 & $0.723^{* *}$ & 0.523 & $0.146^{* *}$ & 0.021 \\
\hline Tra2 & $0.890^{* *}$ & 0.792 & 0.010 & 0.000 \\
\hline Tra3 & $0.901^{* *}$ & 0.812 & 0.005 & 0.000 \\
\hline Tra4 & $0.740^{* *}$ & 0.548 & 0.100 & 0.010 \\
\hline Tra5 & $0.755^{* *}$ & 0.570 & 0.090 & 0.008 \\
\hline Tra6 & $0.730^{* *}$ & 0.533 & 0.110 & 0.012 \\
\hline Ex1 & $0.721^{* *}$ & 0.520 & $0.125^{* *}$ & 0.015 \\
\hline Ex2 & $0.715^{* *}$ & 0.511 & $0.201^{* *}$ & 0.040 \\
\hline Ex3 & $0.754^{* * *}$ & 0.568 & $0.170^{* *}$ & 0.029 \\
\hline Ex4 & $0.845^{* *}$ & 0.714 & 0.030 & 0.000 \\
\hline Ex5 & $0.867^{* *}$ & 0.752 & 0.015 & 0.000 \\
\hline Ex6 & \multicolumn{4}{|l|}{ Dropped } \\
\hline SF1 & $0.806^{* * *}$ & 0.650 & $0.261^{* * *}$ & 0.068 \\
\hline SF2 & $0.759^{* *}$ & 0.576 & -0.120 & 0.014 \\
\hline SF3 & $0.782^{* *}$ & 0.611 & -0.073 & 0.005 \\
\hline OSF1 & $0.863^{* *}$ & 0.745 & $0.229^{* * *}$ & 0.052 \\
\hline OSF2 & $0.915^{* *}$ & 0.837 & -0.070 & 0.005 \\
\hline OSF3 & $0.901^{* *}$ & 0.812 & -0.125 & 0.016 \\
\hline OSF4 & $0.864^{* *}$ & 0.746 & -0.115 & 0.013 \\
\hline $\mathrm{DF} 1$ & $0.893^{* *}$ & 0.797 & $0.176^{* *}$ & 0.031 \\
\hline DF2 & $0.910^{* *}$ & 0.828 & -0.058 & 0.003 \\
\hline DF3 & $0.923^{* *}$ & 0.852 & -0.004 & 0.000 \\
\hline ISF1 & $0.852^{* *}$ & 0.726 & -0.025 & 0.000 \\
\hline ISF2 & $0.878^{* * *}$ & 0.771 & -0.020 & 0.000 \\
\hline Average & 0.813 & 0.666 & 0.079 & 0.017 \\
\hline
\end{tabular}

** significant at a significance level of 0.05 
Table VII: Mediation Effects

\begin{tabular}{|c|c|c|c|c|c|c|c|c|}
\hline IV & MV & DV & $\begin{array}{c}\text { Effect of IV } \\
\text { on MV }\end{array}$ & $\begin{array}{c}\text { Effect of } \\
\text { MV on } \\
\text { DV }\end{array}$ & $\begin{array}{c}\text { Direct } \\
\text { Effect }\end{array}$ & $\begin{array}{c}\text { Indirect } \\
\text { Effect }\end{array}$ & $\begin{array}{c}\text { Total } \\
\text { Effects }\end{array}$ & $\begin{array}{c}\text { 95\% CI for } \\
\text { Mean Indirect } \\
\text { Effect }\end{array}$ \\
\hline ED & OAC & SCF & $0.553^{* *}$ & $0.444^{* *}$ & $0.111^{* *}$ & $0.245^{* *}$ & $0.462^{* *}$ & $0.1408-0.3493$ \\
\hline ED & OL & SCF & $0.538^{* *}$ & $0.198^{* *}$ & $0.111^{* *}$ & $0.106^{* *}$ & $0.462^{* *}$ & $0.0570-0.2153$ \\
\hline
\end{tabular}

